\title{
Design for Recycling Behaviour - An Exploratory Inquiry of Practical Applications
}

\author{
Guillermo Juarez-Bocanegra
}

A thesis submitted to the Faculty of Graduate and Postdoctoral Affairs in partial fulfillment of the requirements for the degree of

\author{
Master of Design \\ in \\ Design
}

Carleton University Ottawa, Ontario

(C) 2020

Guillermo Juarez-Bocanegra 
"Designers are in the behaviour business"

- Fabricant 2009. 


\section{PREFACE}

In the fall of 2018, the author's Master of Design path began at Carleton University. Driven largely by the interest in learning to formulate better solutions for stakeholders. This thesis is the integration of the gained knowledge during this two-year adventure. The narrative follows an academic structure that describes the foundation, then presents the methods and the planned study, to finish the document with the results and the conclusions.

In this project, the approach is clearly described to provide a precise stance to the reader. Moreover, the author revolves around design, elaborating on the role it has played and concludes with thought emerged from this entire process.

Ultimately, this thesis is the instrument to share the knowledge gained and participate in the ongoing discussions in the field. The research was conducted in accordance with the Carleton University Ethics Board, under the supervision of Professor Thomas Garvey, and co-supervisor Professor Mugendi M’Rithaa. 


\section{ABSTRACT}

Efforts geared towards a sustainable development have been progressing in different fields, recently shaping a transitional framework named Circular Economy. In a similar manner, design has produced a collection of significant results, some of them formed the field known as Design for Behaviour Change. This field has produced a series of strategies, models, tools, and methods, by bringing knowledge from the social sciences into design. This project sets out to investigate the scope and limits of one tool in particular-Dimensions of Behaviour Change- by formulating the research question: To what extent, Dimensions of Behaviour Change toolDBC model — can be used in design practice to generate solutions that foster recycling behaviour within circular economy framework? The answer is unraveled in this thesis comprised in five main phases: introduction, literature review, methods, study, and results. Ultimately, this attempts to contribute to the progress of this field. 


\section{ACKNOWLEDGEMENTS}

It is not very often, that objectives follow a straight path. Remaining focused on the goal is a task that demands diligence and a lot, a lot of support. Here, I want to remark my appreciation to everyone who has contributed to the completion of this project.

My supervisor Professor Thomas, my co-supervisor Professor Mugendi M’Rithaa, my examiners Professor WonJoon Chung, and Professor Steven Fai, my family, particularly mom, who always listens. To the City of Ottawa, especially the Waste Management team, who happily supported this project with their time and knowledge. To the Carleton staff, who was always prompted to answer all of my questions and steer me in the right direction. To the colleagues, whose important input assisted greatly in the formation of this document.

And finally, to my partner, Vanessa, whose support and affection for this investigator knows no limits. 


\section{TABLE OF CONTENTS}

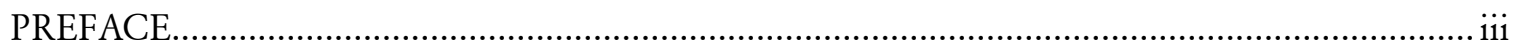

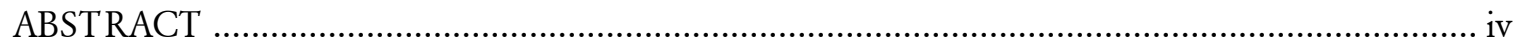

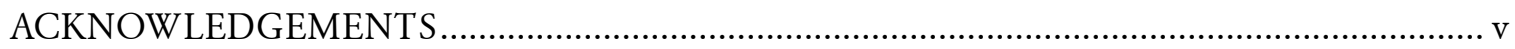

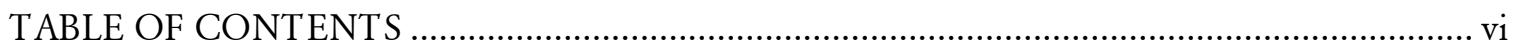

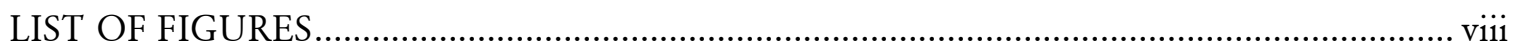

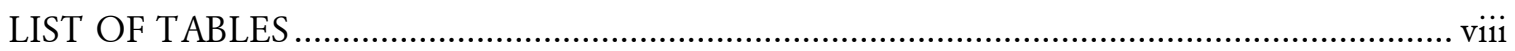

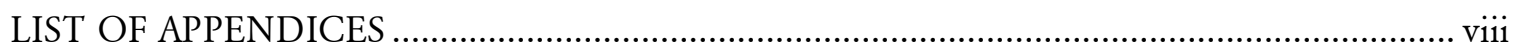

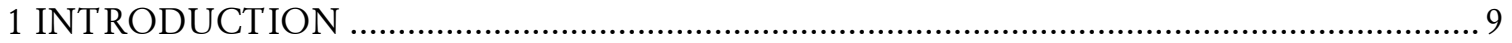

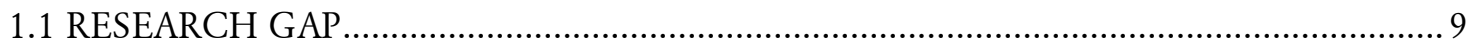

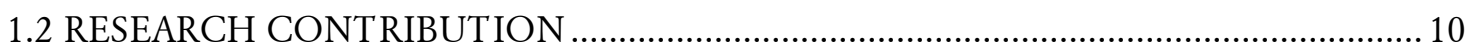

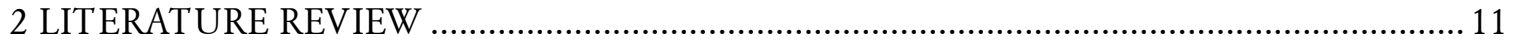

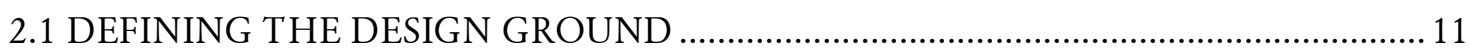

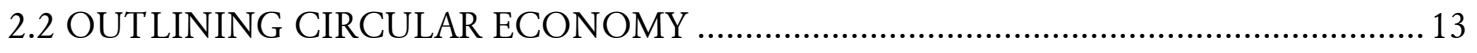

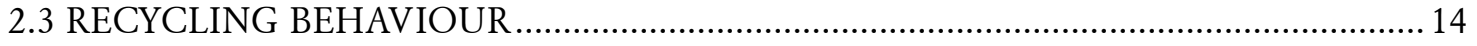

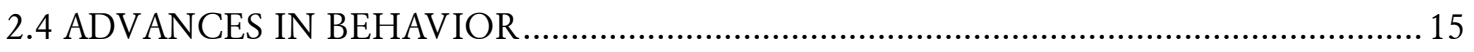

2.5 UNTANGLING THE CONNECTIONS OF DESIGN AND BEHAVIOUR ..................20

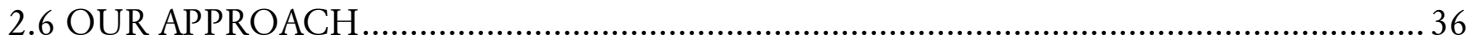

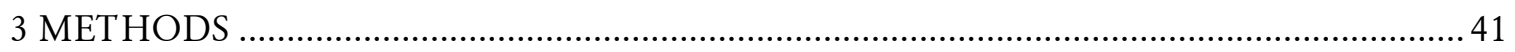

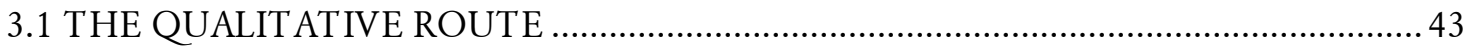

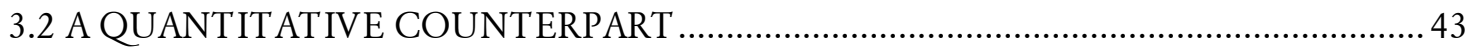

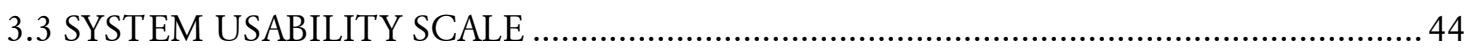

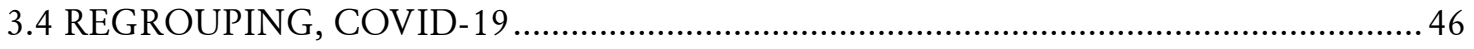

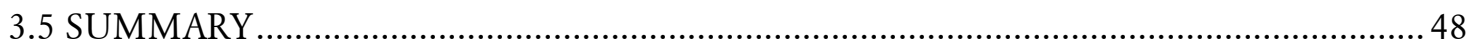

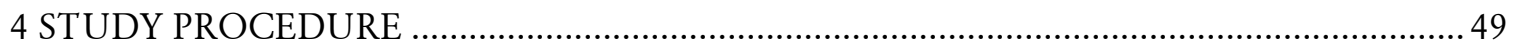

4.1 OUTLINE

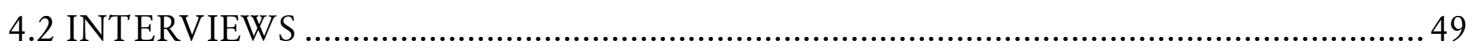

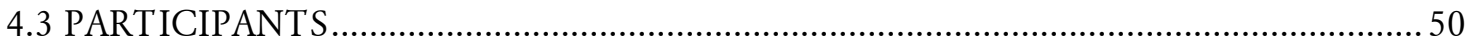

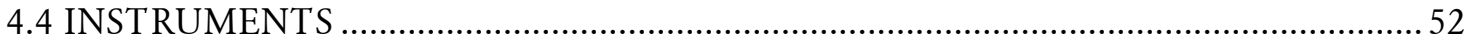

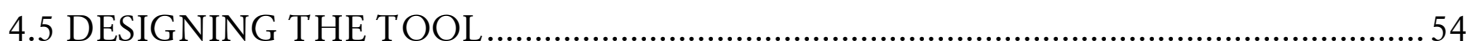




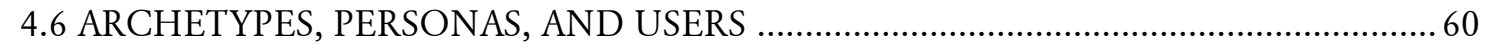

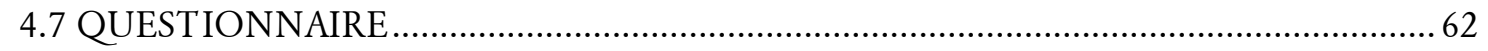

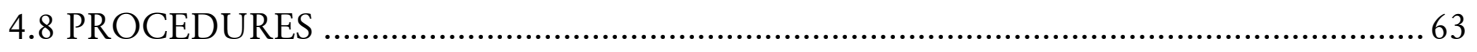

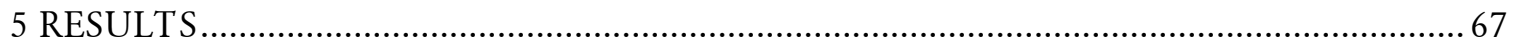

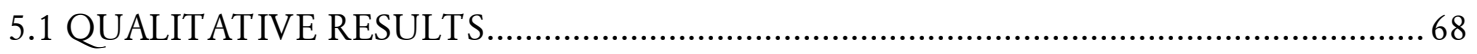

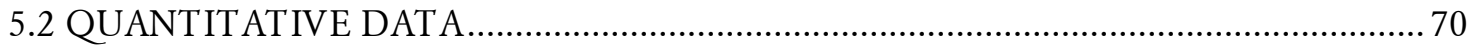

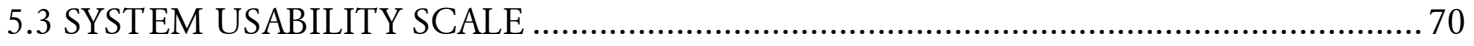

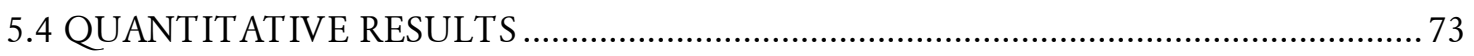

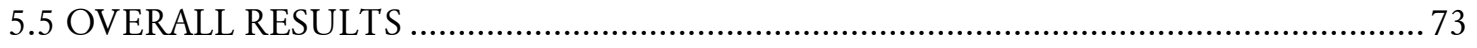

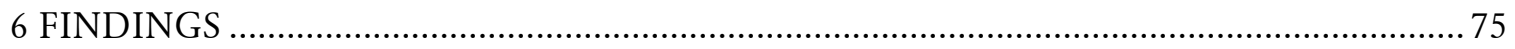

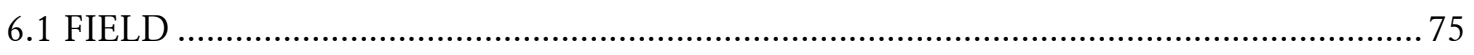

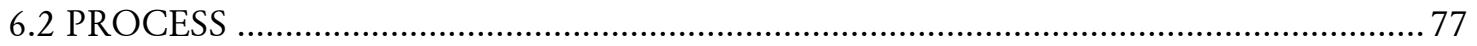

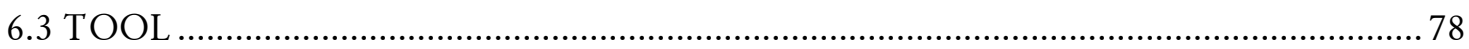

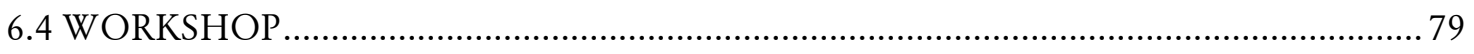

7 DISCUSSION

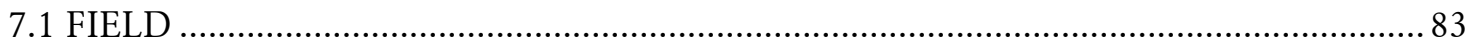

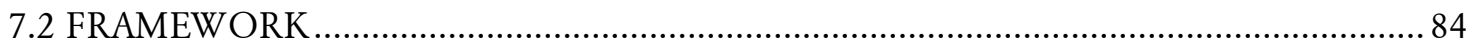

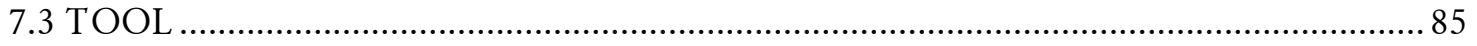

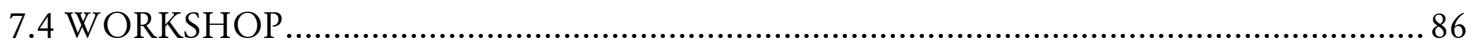

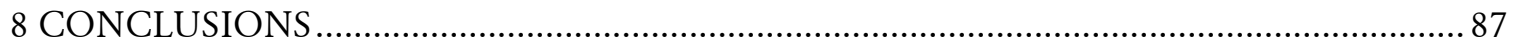

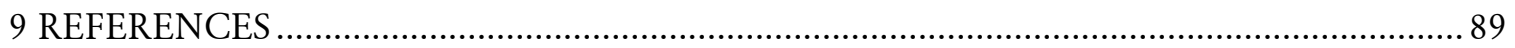




\section{LIST OF FIGURES}

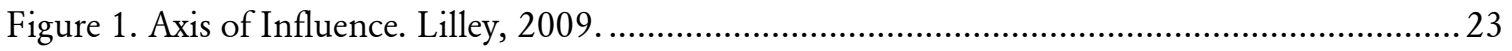

Figure 2. Depiction of Design Behaviour Intervention Model. Tang and Bhamra, 2008............... 23

Figure 3. Depiction of Distribution of Control. Zachrisson et al., 2010 ......................................24

Figure 4. Depiction of Guidelines to Select Design Strategies for Behaviour Change. Zachrisson et al., 2010

Figure 5. Depiction of CADM Model. Klöckner and Blöbaum, 2010 ...........................................25

Figure 6. Depiction of Design with Intent Structure with Inspiration and Prescription Modes.

Lockton, 2012

Figure 7. Depiction of Platform for Persuasion, Ethics and Context Awareness in Persuasive Design.

Gram-Hansen, 2010.

Figure 8. Depiction of The Four Dimensions of Behaviour Framework. Chatterton and Wilson,

2014.

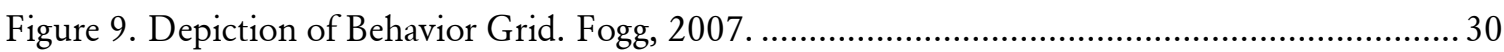

Figure 10. Depiction of Behavior Change Model. Fogg, 2007....................................................... 31

Figure 11. Depiction of The Eight Dimensions of the Eco-Feedback Design Space. Froehlich, 2011.

Figure 12. Depiction of Dimensions of Behaviour Change. Boks and Daae, 2013 ........................ 35

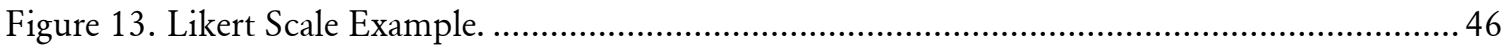

Figure 14. Depiction of Dimension of Behaviour Change - Obtrusiveness Card. Daae, 2013 ......... 55

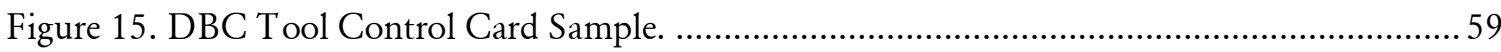

Figure 16. Model for Incorporating Dimensions of Behaviour Change. ........................................62

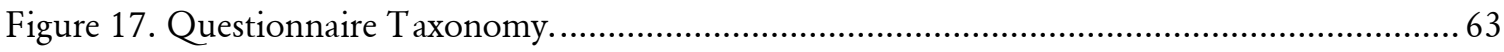

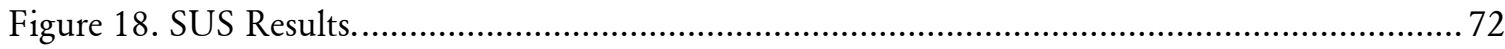

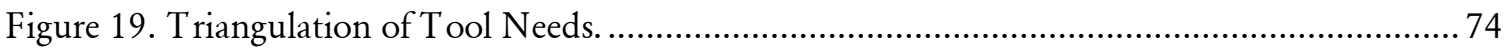

\section{LIST OF TABLES}

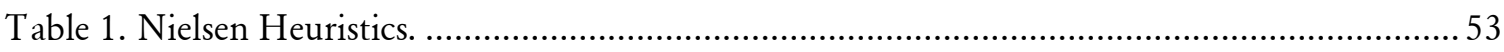

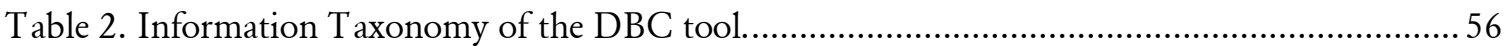

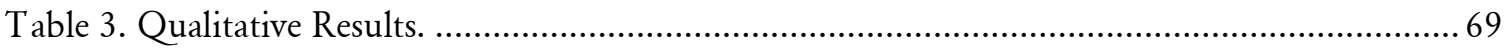

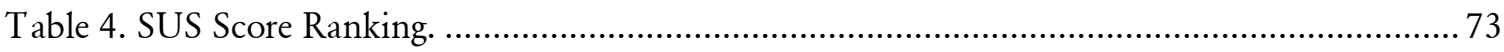

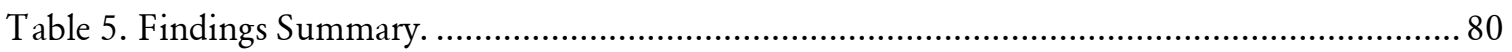

\section{LIST OF APPENDICES}

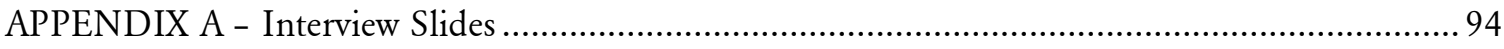

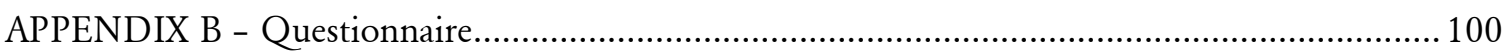

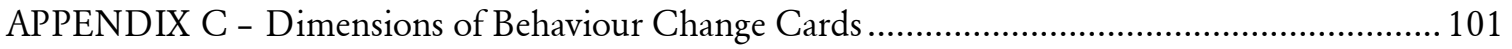




\section{INTRODUCTION}

Sustainable design has been a thriving field over the last decades, and more recently, efforts are aimed at influencing sustainable behaviours through design, forming the Design for Sustainable Behaviour field. This field has developed a collection of strategies, models, and tools aimed at influencing users toward a sustainable goal. One tool in particular, offers a promising but limitedly explored scope of the implementation, Dimensions of Behaviour Change- DBC- tool is the focus of this research. Current reports in the DBC field (Niedderer et al., 2014; Boks et al, 2018; Lilley et al., 2014) acknowledge the need for expanding its proceedings to understand, and further develop the tool(s), striving to aid designers in a more effective manner. Similar tools aimed at design praxis have been revised under a critical design lens Lockton (2013), and present a detailed analysis of the Design with Intent method, elaborating throughout the design decisions of the tool. In a similar approach, this study sets out to design an iteration of the DBC tool based on Human Computer Interaction (HCI) principles, which will be later utilized to collect stakeholders' insights, and finally reporting on the outcomes to produce evidence that supports future directions in the development of this method, and possibly, similar endeavors.

\subsection{RESEARCH GAP}

Design for behavior change emerged as a strategy to aid designers influence stakeholders' behaviour through design. This study aims to answer the question: To what extent, 
Dimensions of Behaviour Change tool- DBC model- can be used in design practice to generate solutions that foster recycling behaviour within circular economy framework?

To answer the formulated question, strategies have been developed striving to guide designers in making concrete connections between design directions and behavior outcomes. This research takes on a qualitative explorational approach, comprised in the form of an online interview, that integrates Dimensions of Behaviour Change tool into the design process to generate solutions that aim to improve recycling behavior in Ottawa, Canada outlined by a Circular Economy framework.

\subsection{RESEARCH CONTRIBUTION}

Proceedings of this study will serve as follows:

A - This research will contribute to expand the scope field of design behavior change. The existing research in the field is limited due to its recent emergence and thus, this research takes on a qualitative and exploratory approach. Contributing specifically to gain a better understanding of the incorporation of the DBC tool in a practical setting, analyzing bothproceedings and feedback. Refining of the tool may also will be possible given the fourresearch-artifacts considered in the study, gathering feedback on the design of the tool by design experts will help future iterations for future efforts.

B- Proceedings of this study will benefit future research in the DfBC field, by offering a detailed report of the current gap. 


\section{LITERATURE REVIEW}

This section presents a structured approach of the reviewed antecedents that delineate this project. It starts by defining the two central concepts in this study- design and behavior- to then provide a theoretical foundation of the intersectional field that emerged from these two disciplines- Design for Behavior Change- summarizing the most significant contributions to this date, underpinning the direction of this study with a conclusion of the literature findings.

\subsection{DEFINING THE DESIGN GROUND}

Defining design is not a simple task, however, it is important for this thesis to establish a common ground for this term. This section will provide a brief collection of definitions that will aid the reader in the upcoming pages. Discussions over the evolving nature and expanding scope of design have been ongoing over decades; this not only defines what design means as a verb, or a noun, but also the debate of whether design constitutes a discipline, a field, or a science. Below, the author presents a collection of contributions developed with the intend of delineating design, such contributions offer a flexible continuum grasp of a concept that has been growing and adapting at a steady pace.

The central theme of design is the conception and planning of the artificial.

-Buchanan (1990, p. 7R) 
As stated above, design may be interchangeably used as a verb, a noun, and an adjective. Its etymological origins can be traced to the Latin word disegnare, which refers to the process of thought and planning. The word design was later introduced to the English language in the 1500s (Friedman, 2000), described by the Merriam-Webster (2020) as "a plan or protocol for carrying out or accomplishing something.”, this contemporary description relates to Papanek's (1985, p. 3), "the planning and patterning of any act towards a desired, foreseeable end constitutes the design process. Papanek's description may be framed as avant garde, any attempt to separate design, to make it a thing-by-itself, works counter to the fact that design is the primary underlying matrix of life". Continuing in this direction, a more recent description that recurrently appears in the literature is Herbert Simon's, who frames design as "any course of action aimed at changing existing situations into preferred ones" (Simon, 1996, page 111). Furthermore, the word design has also become popular as an equivalent for designed artifacts, referring sometimes, to the beautification and cosmetic appearance of the artifacts produced by the design process. This study refers to design as the outcome of design processes, such outcomes may be addressed as products or services as well.

Design also faces another debate, it has been argued inconclusively, that design could constitute a discipline, a field, or a science. Craft origins of design as a practice, due in large part to the physical acts (Friedman, 1997) helped anchoring design in this specific spot. More recently, in the twentieth century, design was recognized as a profession. And even more recently, design became known as a discipline (Friedman, 2000). Such evolving 
changes of design render it elusive to define, these very challenges must be undertaken to shed some light in the underlying connections that are yet to be uncover by research. In this direction, this thesis sets out to contribute to the development of design theory.

To summarize, this section has presented a brief overview of the meanings design as a word, has produced over the course of decades. Comparably, it has been widely agreed the duality of design as a verb, noun, and adjective (Friedman,2000: 8; Gedenryd,1998: 43;

Glanville,1999: 81; Julier,2008: 4; Lawson,2003: 3). Therefore, it is established for the purposes of this thesis, design will be interchangeably used as a process, the proceedings of such process, and, as the field of study. This thesis does not engage in the ongoing debate of what is design, rather it offers a collection of existing descriptions to provide the reader with a comprehensive view.

\subsection{OUTLINING CIRCULAR ECONOMY}

This chapter outlines the foundation from where this project emerged to provide the reader with a richer background. Current needs at a global scale have encourage several disciplines to turn towards sustainable endeavors. Sustainability has inhabited the minds of both, scholars, and non-scholars over decades. Efforts made, have resulted in a numerous collection of strategies, tools, and methods, all aimed at achieving important progress towards a global goal. Despite these attempts, sustainability still remained in the horizon. Such challenges derived in a stage that has been developed as a transitional bridge known as Circular Economy (CE). Circular Economy framework has been discussed since the 1970's, rooted in 
the environmental movements, described as "an economy with closed material loops" (Wautelet, 2018, p.1). It is agreed that CE incorporates a holistic framework in relation to previously proposed models (Wautelet, 2018 p. 25), described in the three founding principles- preserve and enhance, optimize resource yields, and foster system effectiveness. The adoption of circular economy in European countries emerged through waste policies in 1976, highlighting the recycling principle of a CE. The factors listed in the circular economy model are several, however, this study addresses the recycling phase, which refers the reincorporation of waste into the production cycle.

\subsection{RECYCLING BEHAVIOUR}

Substantial attention has been paid to recycling behaviour by different disciplines. It is not the purpose of this study to analyze, nor evaluate the performance of the tool at improving recycling behaviour, rather, this thesis focuses on whether the tool is capable to aid designers improve recycling behaviour, and, if positive, to what extent. Following this direction, this section overviews some efforts in the fields of design, sociology, and psychology, to then move onto the theoretical foundation that connects design with behaviour. Different studies that are focused at the intersection of recycling-behavior and design have helped in elucidating the effects of different inputs such as the physicality of the objects (Trudel and Argo, 2013), and the effects signage design has on recycling behavior (Wu et al., 2018). Similar studies are taking place, utilizing design to uncover behavior insights from different angles. Most recent endeavors aim to uncover frameworks that may help achieve results in a 
circular economy. Recent efforts in design have developed a collection of fields that aim to foster sustainable behaviours, in this manner, Design for Sustainable Behaviour, is part of the larger umbrella Design for Behaviour Change.

\subsection{ADVANCES IN BEHAVIOR}

This section will introduce behavior to link its origins in social sciences with current efforts in design. It briefly addresses sociology efforts, then focuses on behavioral psychology and a brief overview of existing theories, and models that approach behavioral frameworks. A conclusion of the literature regarding behavior, supports the research approach that will aid the fulfilment of the purposes of this study. It is equally important to mention that this study has no interest in arguing the best theoretical approach to either field- Design for Sustainable Behaviour nor Design for Behaviour Change- this research limits to provide an overview of the approaches that have similar, and/or shared goals, focusing on expanding the existing research of the incorporation of the Dimensions of Behaviour Change tool developed by Daae and Boks (2014). If further research is needed to investigate the validity of the theoretical approach to either of the fields, it may be undertaken at a different time in the future. Although it has been argued that there is not an adequate definition of behavior (Bergner, 2011), this study lacks the intent to participate in the ongoing discussion regarding the concept of behavior. Thus, this limits its scope to the most recognized definition, that establishes behavior as an observable response to a stimulus or factor in an individual's to its internal or external environment (Watson, 1994). On this view, different fields have 
undertaken the task to study such a complex topic. Sociology and psychology have produced most of the contributions to the behavior field. Such efforts have produced a foundation from which design has been drawing theories, models, and strategies. In the following paragraphs, both fields are described briefly, lastly, the section concludes with a summary, supporting the selection of the tool and its theoretical ground.

\subsubsection{PSYCHOLOGY AND SOCIOLOGY-BEHAVIOUR AND PRACTICE}

It has been widely recognized that drawing from social sciences' existing models and theories may benefit design in behavioural endeavors (Lockton, 2013; Pettersen, 2013; Wilson, 2013). This study builds majorly on prior efforts done by Boks (2014), where he explores and contrasts the two dominant perspectives in behaviour- Practice Theory from Sociology and Behaviour Models from Psychology. Boks focuses on such models based on previous studies that suggest these two approaches may have a potential to support the development of the design field in behaviour ventures.

\subsubsection{A DESCRIPTIVE VIEW OF PRACTICE THEORY}

This section describes practice theory, its views, and the overall connection to design in the behaviour scope. The work of Bourdieu (1977) is considered to have originated practice theory, becoming an important tool in Sociology to understanding how and why people interact with their surroundings. In this perspective, practice is defined as "a routinized type of behaviour which consists of several elements, interconnected to one another" (Reckwitz, 2002 p. 249). Another definition also recognizes practices as a social phenomenon, in the 
sense that, firstly, "participating in them entails immersion in an extensive tissue of coexistence that embraces varying sets of people", and, secondly, their organization is part of the "nexuses of doings and sayings that compose them" (Schatzki 2002, p. 87). Due largely in part to its relevance in the study of interactions between people and their environment, the possibility of building a connecting model that will inform design behavioural outputs has been argued by Pettersen (2013). A series of strategies based on practice theory, to inform designers have already been developed, to mention the work of Shove et al. (2007, 2010) who structured the elements in a useful manner for designers; images, stuff, and skills. This view has been dominating recent investigations into how design processes can be informed by practice theory as Boks (2014) reports.

\subsubsection{APPROACHING BEHAVIOURAL PSYCHOLOGY}

This section overviews the behavioural psychology perspective, to explore the potential connection with design in the following sections. The origins of behavioural psychology can be recognized in the work of Watson (1913), as he describes in Psychology as the Behaviorist Views It (p. 248), "the goal of this field is the prediction and control of behaviour", this view is supported by Daae (2014, p. 52), who states that "social psychological understanding of behaviour builds on the notion that it is possible to understand the reasons people behave the way they do and identify the individual factors that may affect the behaviour.”. Given the purpose of the field, Daae (2014) recognizes that psychology has significantly contributed to the emergence of the field Design for Sustainable Behaviour. 
Moreover, some design researchers have developed frameworks founded directly on specific behavioural models, like Bhamra et al. (2008), and Tang (2010). As it is mentioned above, behavioural psychology models take on the individual scope rather than a social one and elaborates on the reason that behaviour can be divided into individual factors (Stern, 2000).

Such models aim to explain why people behave in the manner they do, and possibly improve their predictive ability, they achieve this by identifying the individual factors involved in the behaviour phenomena. The number of identified factors varies greatly among models, the more comprehensive a model strives to be, the larger the number of factors is. Additionally, the labels and categories used to identify different factors are not consistent throughout the field.

\subsubsection{SUMMARY AND CONCLUSIONS}

This section has presented an overview of the two dominant perspectives into behavior from both fields: sociology, and psychology, that recognize the input artifacts and systems have in shaping behavior (Latour, 1992, Akrich, 1992, Nelson and Stolterman, 2012). The author builds on the arguments presented in Daae's thesis (2014) to underpin the selection of the Dimensions of Behaviour Change tool, as the subject of study in this project. The supporting argument Daae offers to select behavioural psychology frameworks over practice theory is described below.

After presenting an overview of both dominating perspectives- social practice and behavioural psychology - Daae (2014) highlights arguments that shed light on the capability 
of both perspectives to inform design models. In a similar approach, it is argued by Pettersen (2013), that Practice Theory is a preferred ground over Social Psychology to develop models within design. Her conclusion is drawn after having identified a number of benefits and disadvantages from these two fields. She argues that the limited attention paid to the interactions between humans and technology offered by social psychology, makes the more comprehensive scope of practice theory her preferred approach.

All in all, Daae recognizes the limits of embarking on a narrower perspective as social psychology outlines it. As reviewed above, both fields approach the phenomena from different perspectives, practice theory draws on a social scope that englobes a broader collection of factors. Although, benefits of building on social practice appear to have a more comprehensive landscape, as Pettersen (2013) argues and Daae (2014) acknowledges, Daae highlights the more aligned perspective of social psychology to address specific steps, as is the case of his research, in the context of individual interactions between individuals and artifacts. Concluding that, "social practice considers practices to be connected in systems (Pantzar and Shove, 2010) and does not focus on specific interactions at a product-user level, and does not provide a similarly detailed and nuanced framework for analyzing the factors affecting the interaction." On the other hand, "behavioural models from social psychology are therefore considered a more suitable view to inform the design of products aimed at resulting in a particular behaviour.” 


\subsection{UNTANGLING THE CONNECTIONS OF DESIGN AND BEHAVIOUR}

So far, this document has established some reference points that define design and behaviour.

The following section tackles the overlap of these fields, to prepare the stage for the main

argument of this thesis. First, the researcher will review existing ventures in design that aim

to bridge behavioural theories and design to produce frameworks. Secondly, the focus will

frame the DBC tool, describing its features and background that will support our approach.

Finally, the researcher will conclude this section with a summary of the literature review

before moving forward onto the methods chapter.

The connection between design and behavior is widely acknowledged in both design and

psychology fields. Attention to this relationship emerged in social sciences and, as mentioned

above, these connections are recognized by Watson, (1913) Akrich, (1992) and Latour

(1992). Similarly, in design this relationship has been highlighted by Norman (1988), who

initially used the term coined by J. J. Gibson (1977) of affordances, which refers to the

perceived and actual properties of an artifact, primarily those fundamental properties that

determine just how the artifact could possibly be used (Norman, 1988). This notion is quite

important because it provides a series of features to the user in the context of interaction, that

limit or enable different outcomes. This foundation enabled further studies and helped in

illustrating the importance of this ubiquitous relation under the design lens. It is important

to mention that Norman's initiative focuses on improving user's experience, rather than

shaping their behaviour. 
After having recognized the agency artifacts have in shaping behaviour, the author now overviews some of the most significant efforts in design, significant in the context of the most cited and discussed over the last decade.

A collection of enterprises started flourishing over the last decade in design that tackled the connection between behaviour and artifacts. The goals of such endeavors vary greatly from one to another, not only in the sense of goals, but also in the terminology employed. These variations and lack of uniformity in the efforts, lay in part to the recent emergence of the field, which for the purposes of this thesis the author will refer to as Design for Behaviour Change (DfBC). This definition is described in one of the most recent proceedings in the field (Niedderer, et al., 2016) and the researcher will use it to englobe the variants: Design for Sustainable Behaviour, Design for Behaviour Change, and Behavioural Design. Although, different agendas may strive for different purposes, research efforts in design focused on behaviour, such as strategies, models, and, tools, all draw on a similar foundation.

It is considered that one of the first endeavors in the field, from which the field may have originated, the work of Jaap Jelsma, (1997) who built on Akrich's (1992) concept of scripts, influenced the way people interact with products to reduce environmental impact. It has also been noted by Verbeek and Slob (2006), that a previous attempt was done by Achterhuis in 1995, who drew on Latour's (1992), concept of scripts, to develop what he called moralization of technology. These initial explorations, drawn from social sciences, served to nurture most of contemporary proceedings in the field. 
The collection of approaches mentioned below, follows a quasi-chronological order. Expansion of the field continued in the early 2000's when Lilley (2006) identified what she calls, the axis of influence, that describes the decision-making power spectrum, between user and product. Elaborating further, Lilley (2009) formulates three agency levels to influence behaviour- eco-feedback, behaviour steering, and persuasive technology - these categories offer the following levels of control. Eco-feedback is established at one end of the axis, and is considered to be a non-coercive approach (Wilson, 2013) intended to guide the user with sensorial feedback (visual, aural, or tactile) to enable the user with the decision-making control. In the middle of the axis is where behaviour-steering finds its place, this approach builds on Jelsma and Knot's (2002) concept of scripts and expands it to include Norman's (1988) notion of affordances. The control is shared between user and artifact in this approach, following a scripting perspective, designers would shape product affordances to frame explicit potential actions, and define constrains to make explicit potential limitations. The limits of what users can and cannot do are explicitly embedded in the characteristics of the artifact. Conversely, on the opposed end of the axis is persuasive technology which widens its scope to include coercive strategies to secure change (Wilson, 2013). Similarly, Wever et al. (2008) developed a categorization that considers three similar branches: ecofeedback, scripting, and forced functionality. The resulting axis is then stretched to include a fourth category - functionality matching - that frames the opposed intentions between user's intend and product' functionality. As Wilson (2013) reports, this new category, as well as 
that listed by Lidman et al. (2011) - enabler - and the three divisions proposed by Elias

(2011), fall in the initial categories proposed by Lilley (2009). See Figure 1.

USER $\leftarrow$ Eco Feedback

Behaviour Steering — Intelligent Products

PRODUCT

INFLUENCE

Figure 1. Axis of Influence. Lilley, 2009.

Consequently, efforts that built on Lilley's axis of influence, resulted in the formulation of

the Design Behaviour Intervention Model -DBIM. Proposed by Tang and Bhamra (2008)

(see figure 2), this model draws on Triandis' Theory of Interpersonal Behaviour (Triandis, 1977), Anderson's theory of development of cognitive skills (Anderson, 1982), and is

distributed along the axis of control (Lilley, 2006). The model describes different strategies to design interventions according to different stages of behaviour change.

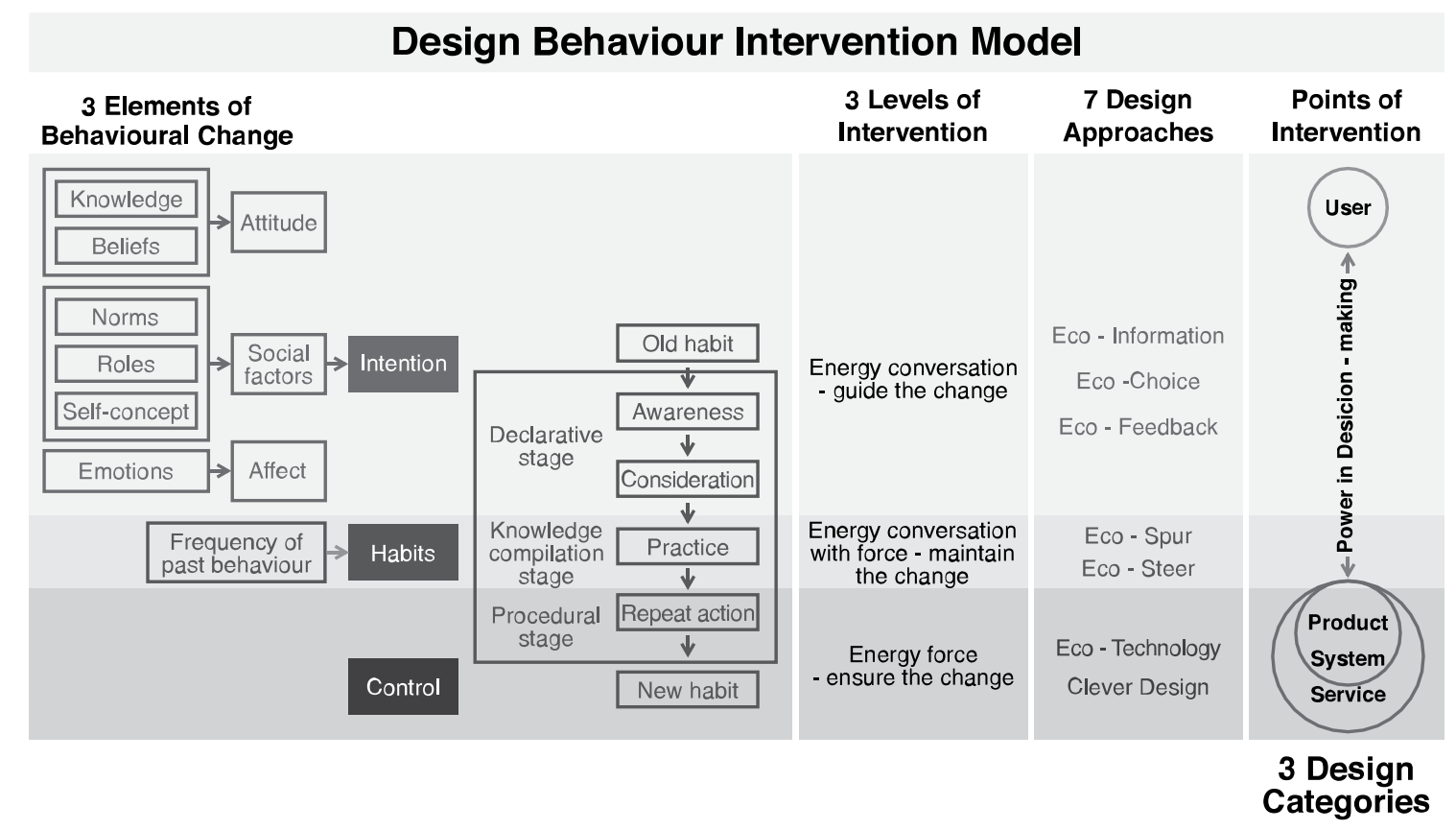

Figure 2. Depiction of Design Behaviour Intervention Model. Tang and Bhamra, 2008. 
As the decade progressed, the attention to the emerging field became more visible with doctoral efforts aimed at uncovering the underlying connections between behaviour and artifacts. Zachrisson et al. (2010) contributed with a set of publications aimed to expand and develop knowledge in the recent field. The work is broken down into two parts: first, Zachrisson et al. segmented the axis of control into defined categories (see Figure 3).

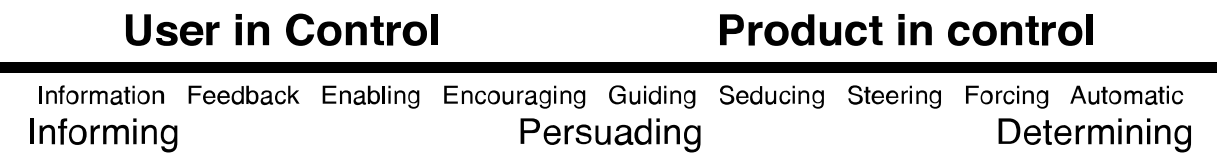

Figure 3. Depiction of Distribution of Control. Zachrisson et al., 2010.

This initial approach was developed in parallel with guidelines to select strategies for behaviour change, (Zachrisson et al., 2010). Such guidelines (see Figure 4) draw on the model created by Klöckner and Blöbaum (2010), as they highlight the promising framework identified in the model. The model named Comprehensive Action Determination ModelCADM- (see Figure 5) combines frameworks from both perspectives- psychology and sociology- described at the beginning of this chapter. Zachrisson et al. argue that the complementary foundation of the model, offers wholesome scope, to undertake behavioural changes from a design perspective at both levels- personal and contextual. Additionally, Zachrisson (2010) outlined a process to design a behaviour change, which will be described in detail below in this thesis. 


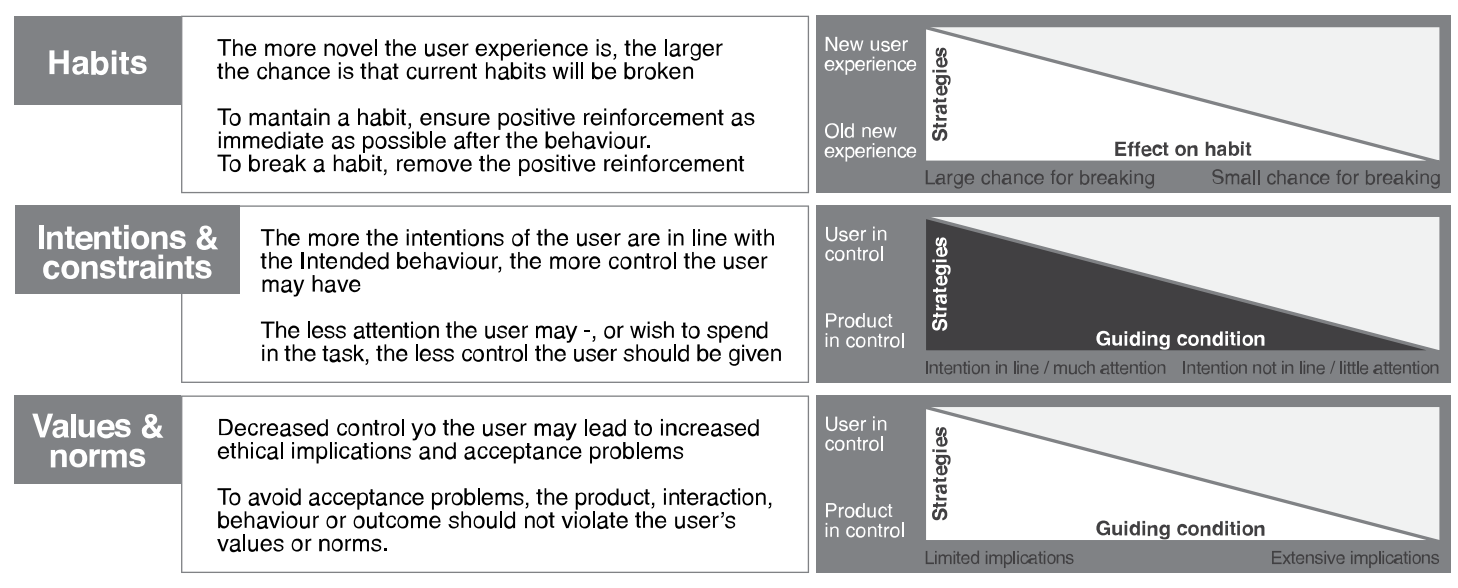

Figure 4. Depiction of Guidelines to Select Design Strategies for Behaviour Change. Zachrisson et al., 2010.

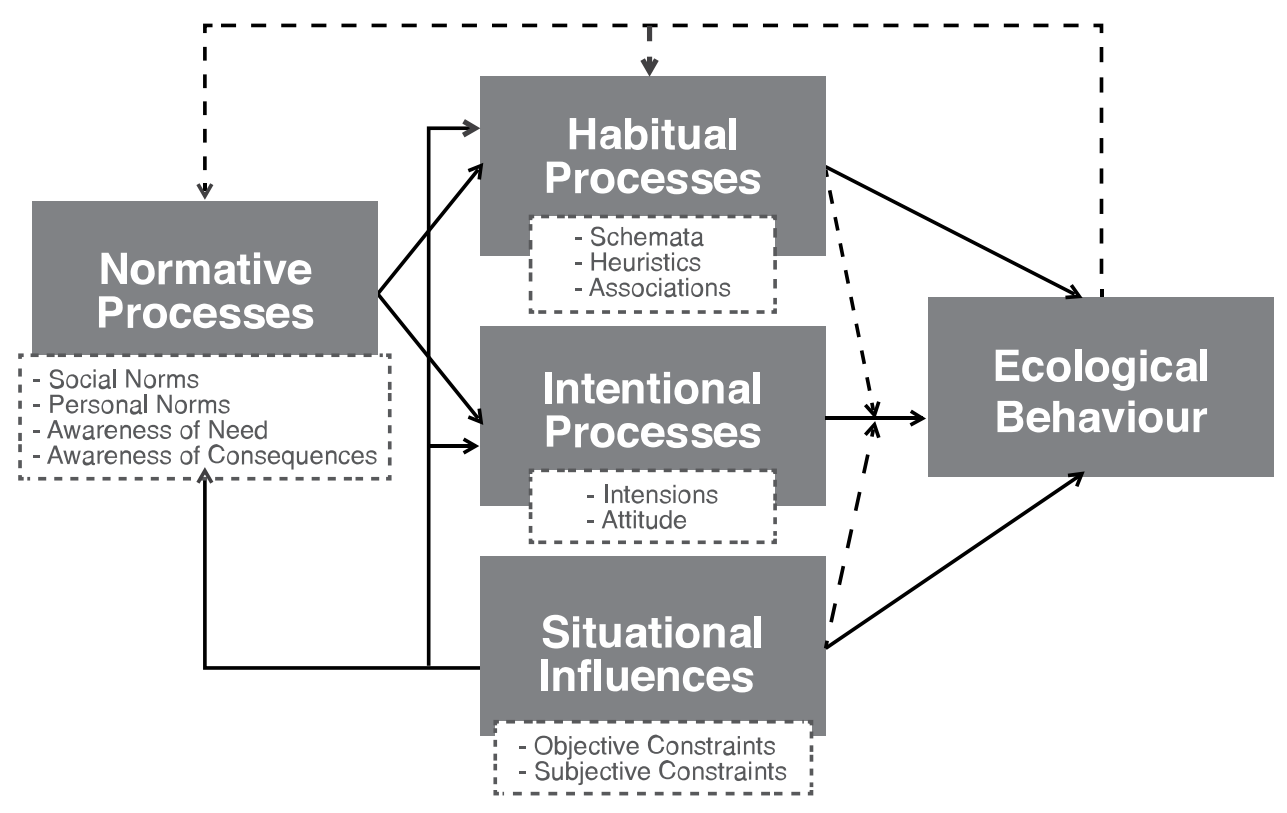

Figure 5. Depiction of CADM Model. Klöckner and Blöbaum, 2010.

The following effort was developed as a toolkit. Design with Intent- DwI- is a method produced by Lockton (2010) aimed at helping designers generating ideas for behaviour change. This tool is the result of Lockton's efforts that originated in 2005 in his thesis Architectures of Control in Consumers Products. As he defines it "Architectures of control are features, structures or methods of operation designed into physical products, software, 
buildings, city layouts - or indeed any planned system with which a user interacts- which are intended to enforce, reinforce, or restrict certain modes of user behaviour.” $(2005$, p. 1). This initial exploration follows his initial lead- "products and systems can be engineered and designed with rationales and intentions behind them beyond the prima facie functionality or appearance requirements of a conventional specification or brief” (p. 1). Although the phenomenon is not new, it deserves attention from the field. Moving forward, Lockton then introduced the Design with Intent method, which consists of six lenses- architectural, error proofing, persuasive, visual, cognitive, and security - to support designers during the creative process. The method is described to have two different modes of use- inspiration and prescription - both modes are described in Figure 6. Although the method emerged as a solution to improve environmental behaviour in users', Lockton (2010) has highlighted that the method is intended to be useful in any challenge in which behaviour change is targeted. DwI method offers a rich contribution as more proceedings continue to surface. Endeavors in this direction uncover important findings but more importantly, they generate more questions: one being priority for the purposes of this thesis, would be to find the most convenient way to incorporate this tool in the design process. Lockton outlines a clear model where the DwI method is intended to fit (see Figure 7) according to Gram-Hansen (2010). The author will address this question further in this document. Additionally, Lockton et al. (2012) point out the attention needed to understand users' behaviour for the kit to perform better, to support users accomplish this. Lockton et al. (2012) present a user-modeling 
framework - pinball, shortcut, and thoughtful- that aims to help designers shape more

precisely their users to have a more effective approach when using behaviour change

strategies. This notion will also serve as part in our discussion in our approach and

methodologies sections.

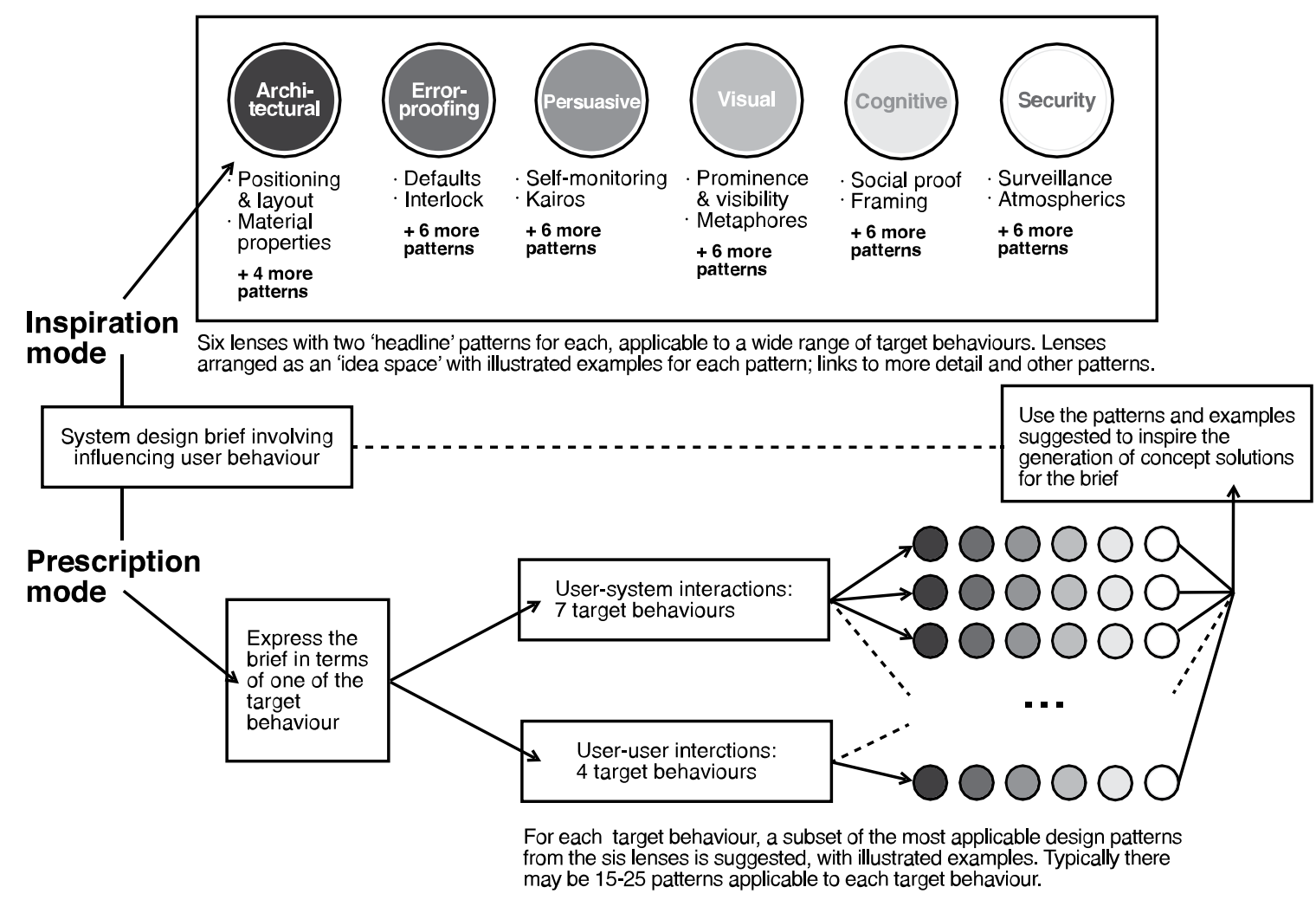

Figure 6. Depiction of Design with Intent Structure with Inspiration and Prescription Modes. Lockton, 2012. 


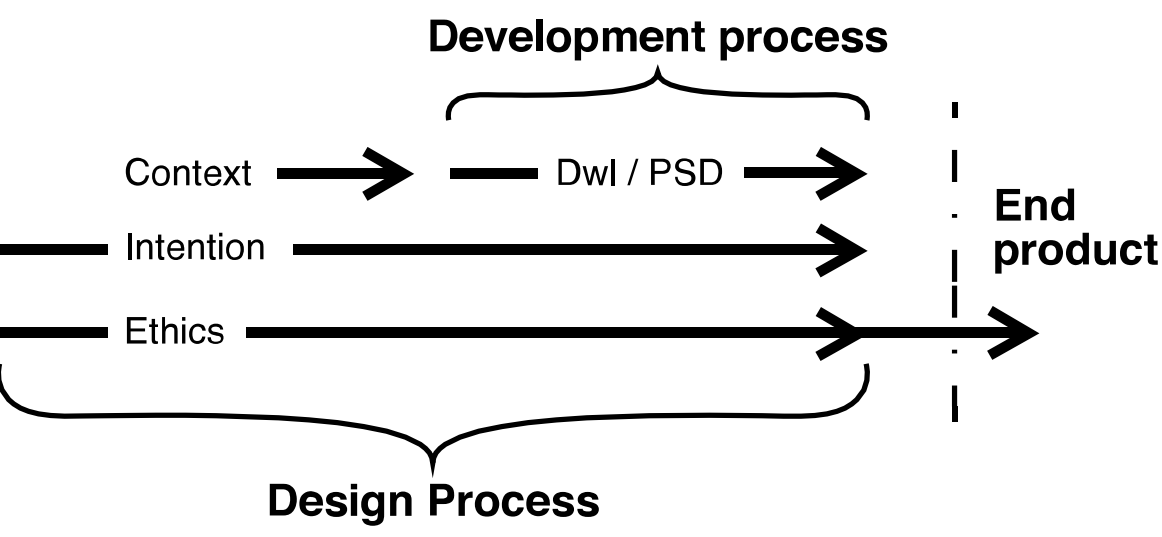

Figure 7. Depiction of Platform for Persuasion, Ethics and Context Awareness in Persuasive Design. GramHansen, 2010.

A more recent work is the Four Dimensions of Behaviour framework, developed by Chatterton and Wilson (2014). It is a tool intended to help design better interventions. Drawing from both dominant fields- psychology and sociology- the tool offers some new perspectives to the design for behaviour change field. It is important for this thesis to point out the interdisciplinary view of the tool, as Chatterton and Wilson (2014, p.44) report. It is developed to support intervention designers and policy makers. In contrast to the previously reviewed tools, this approach considers two different stakeholders. A stance that serves to underline the multidisciplinary character of this field, such a topic will be discussed later in this thesis. Continuing with the description of the tool, it depicts two axes- dimensions, and levels- four dimensions include: actor, domain, durability, and scope. Each of these dimensions are then divided by a spectrum of five levels (see Figure 8). The tool has endured testing and iterations have reported promising outcomes (Chatterton and Wilson, 2014). 


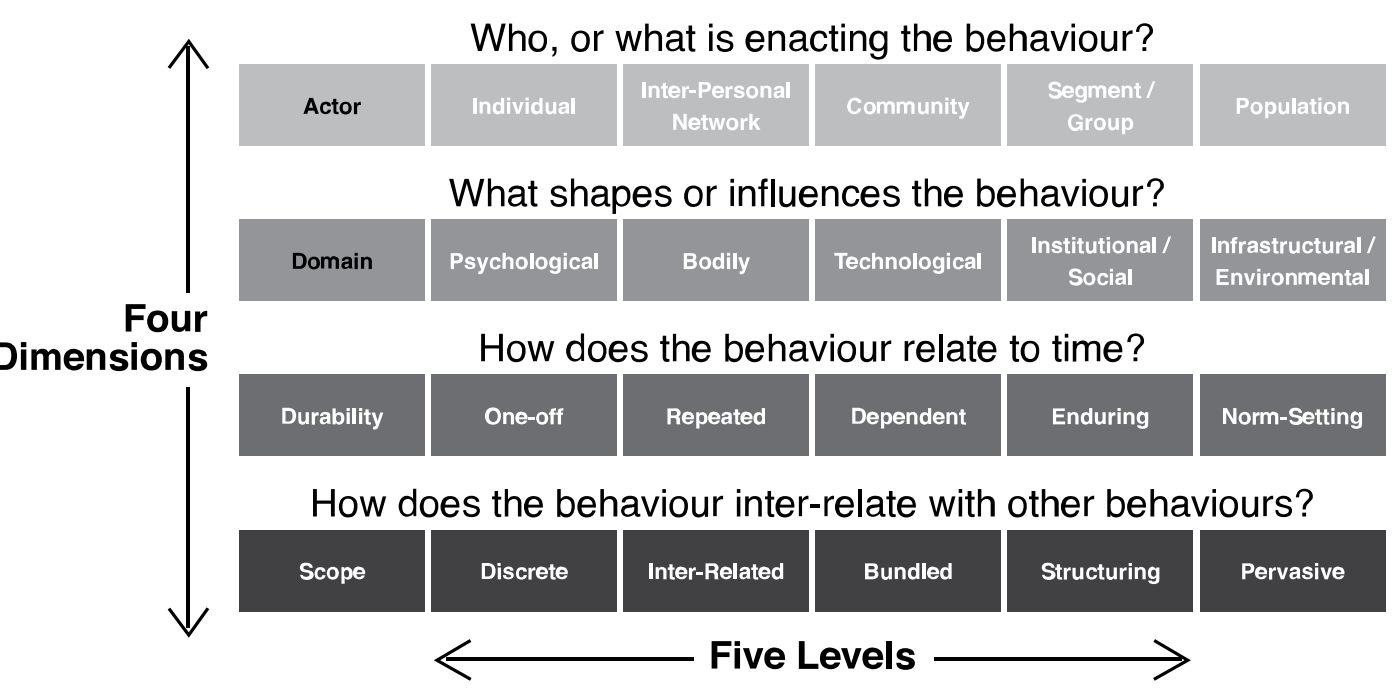

Figure 8. Depiction of The Four Dimensions of Behaviour Framework. Chatterton and Wilson, 2014.

In a parallel path, HCI field has been expanding research over the behaviour topic at a constant pace. The term Persuasive Technology was first introduced by Cialdini (1993) and later expanded by Fogg, who describes it as "an interactive product designed to change attitudes or behaviors, or both, by making a desired outcome easier to achieve” (2003, p. 32). Fogg later expands the initial set of strategies to develop the Behaviour Grid (2007). The grid observes 35 types of behaviour change. Later on, Fogg elaborates further and refines the grid in a latter iteration (2010) (See Figure 9), which depicts a reduction of 15 types in comparison to the initial 35 types set. Two axes are observed in the grid. On the vertical axis lies the duration of the trigger- dot, span, and, path- and on the horizontal axis, the type of change of the behaviour is found- initiate, reinitiate, increase, decrease, and stop. The grid aims to help understanding the better strategy to follow, based on the type of change one is striving to achieve. 
Fogg Behaviour Grid BehaviourGrid.org

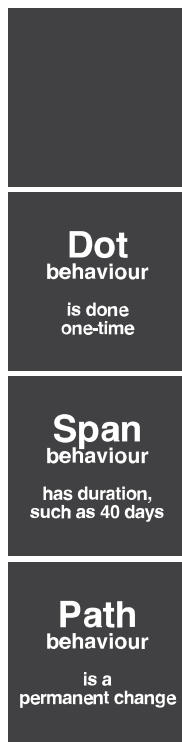

\begin{tabular}{|c|c|c|c|c|}
\hline$\underset{\text { behaviour }}{\text { Green }}$ & $\begin{array}{l}\text { Blue } \\
\text { behaviour }\end{array}$ & $\begin{array}{l}\text { Purple } \\
\text { behaviour }\end{array}$ & $\begin{array}{c}\text { Gray } \\
\text { behaviour }\end{array}$ & $\underset{\text { behaviour }}{\text { Black }}$ \\
\hline $\begin{array}{l}\text { Do new } \\
\text { behaviour one } \\
\text { that is unfamiliar }\end{array}$ & $\begin{array}{l}\text { Do familiar } \\
\text { behaviour }\end{array}$ & $\begin{array}{l}\text { Increase behaviour } \\
\text { intensity } \\
\text { or duration }\end{array}$ & $\begin{array}{l}\text { Decrease behaviour } \\
\text { intensity } \\
\text { or duration }\end{array}$ & $\begin{array}{l}\text { Stop doing } \\
\text { a behaviour }\end{array}$ \\
\hline Green Dot & Blue Dot & Purple Dot & Gray Dot & Black Dot \\
\hline $\begin{array}{c}\text { Do new behaviour } \\
\text { one time }\end{array}$ & $\begin{array}{l}\text { Do familiar } \\
\text { behaviour one time }\end{array}$ & $\begin{array}{l}\text { Increase behaviour } \\
\text { one time }\end{array}$ & $\begin{array}{c}\text { Decrease behaviour } \\
\text { one time }\end{array}$ & $\begin{array}{c}\text { Stop doing a } \\
\text { behaviour one time }\end{array}$ \\
\hline $\begin{array}{l}\text { Install solar panels } \\
\text { on house }\end{array}$ & $\begin{array}{l}\text { Tell a friend about } \\
\text { eco-friendly soap }\end{array}$ & $\begin{array}{l}\text { Plant more trees } \\
\text { and local plants }\end{array}$ & $\begin{array}{l}\text { Buy fewer boxes of } \\
\text { bottled water }\end{array}$ & $\begin{array}{c}\text { Turn off space } \\
\text { heater for tonight }\end{array}$ \\
\hline Green Span & Blue Span & Purple Span & Gray Span & Black Span \\
\hline $\begin{array}{l}\text { Do new behaviour } \\
\text { for a period of time }\end{array}$ & $\begin{array}{l}\text { Do familiar behaviour } \\
\text { for a period of time }\end{array}$ & $\begin{array}{l}\text { Increase behaviour } \\
\text { for a period oftime }\end{array}$ & $\begin{array}{l}\text { Decrease behaviour } \\
\text { for a period of time }\end{array}$ & $\begin{array}{l}\text { Stop doing a behaviour } \\
\text { for a period of time }\end{array}$ \\
\hline $\begin{array}{l}\text { Carpool to work for } \\
\text { three weeks }\end{array}$ & $\begin{array}{l}\text { Bike to work for two } \\
\text { months }\end{array}$ & $\begin{array}{l}\text { Take public bus for } \\
\text { one month }\end{array}$ & $\begin{array}{c}\text { Take shorter showers } \\
\text { this week }\end{array}$ & $\begin{array}{l}\text { Don't water lawn } \\
\text { during summer }\end{array}$ \\
\hline Green Path & Blue Path & Purple Path & Gray Path & Black Path \\
\hline $\begin{array}{l}\text { Do new behaviour } \\
\text { from now on }\end{array}$ & $\begin{array}{l}\text { Do familiar behaviour } \\
\text { from now on }\end{array}$ & $\begin{array}{l}\text { Increase behaviour } \\
\text { from now on }\end{array}$ & $\begin{array}{l}\text { Decrease behaviour } \\
\text { from now on }\end{array}$ & $\begin{array}{l}\text { Stop a behaviour } \\
\text { from now on }\end{array}$ \\
\hline $\begin{array}{l}\text { Start growing own } \\
\text { vegetables }\end{array}$ & $\begin{array}{l}\text { Turn off lights when } \\
\text { leaving room }\end{array}$ & $\begin{array}{l}\text { Purchase more local } \\
\text { produce }\end{array}$ & $\begin{array}{l}\text { Eat less meat } \\
\text { from now on }\end{array}$ & Never litter again \\
\hline
\end{tabular}

Figure 9. Depiction of Behavior Grid. Fogg, 2007.

In a similar vein, Fogg (2009) developed the behavioural model for persuasive technology

(see Figure 4), this model shows the correlation between motivation and ability for the

trigger to have a successful outcome. It is important to mention that the behavioural model

poses strong similarities to Ölander and Thørgersen’s (1995) Motivation-Ability-

Opportunity model. 


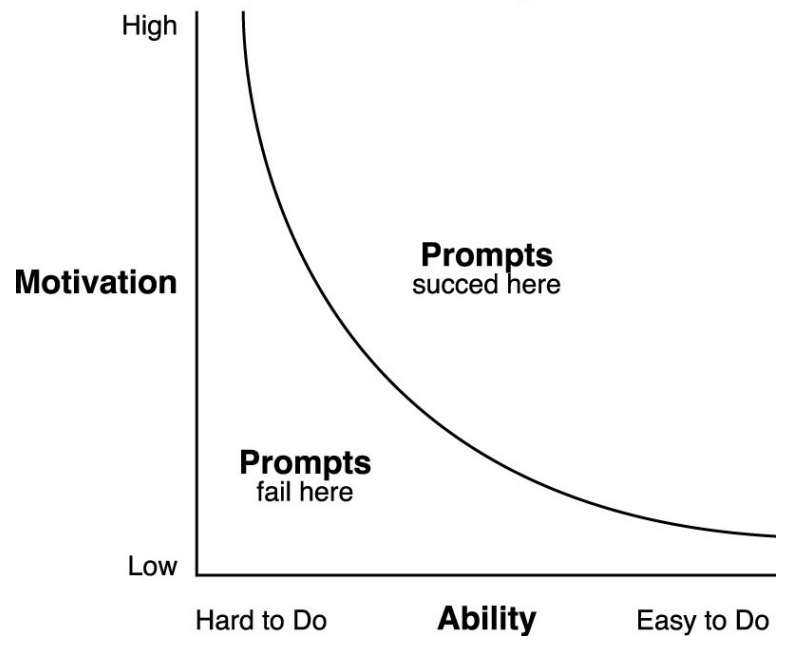

Figure 10. Depiction of Behavior Change Model. Fogg, 2007.

It is worth mentioning a similar proceeding in the HCI field. Froehlich (2011) built on studies of feedback mechanisms and their effect, and later, identified and categorized eight dimensions of the Eco-Feedback design space (see Figure 11). This tool was developed by drawing on existing literature in the HCI field, depicting dimensions that inform designers how different design aspects may be adjusted. Visualized data, accessible data, actionable data, and motivational factors: these aspects are broken down into eight dimensions with subcategories and spectrums. Froehlich (p. 95) also recognizes that these dimensions are not entirely orthogonal; indeed they intersect. This concludes that the key to this tool resides in helping to structure the design process.

So far, this section has presented a collection of the most discussed endeavors in design for behaviour change, making undeniable the interdisciplinarity of the field. However, the focus must return to the core of this thesis. This section limits to present features, connections of 
the tool in relation to proceedings, and to describe the tool without debating those mentioned features. Discussion will take place further in this document. After establishing that this thesis aims to expand the current knowledge on the DBC tool, it may be described as the underpinning ground for this document. Dimensions of Behaviour Change is a tool intended to aid designers who undertake behaviour changing challenges (Daae and Boks, 2017). It was developed by collective efforts at the Norwegian University of Science and Technology- NTNU- (Zachrisson et al., 2011; Boks and Daae, 2013) in an iterative process that builds on Principles of Behaviour Change (Zachrisson et al., 2011; Boks and Daae, 2013). Based on the Principles of Behaviour Change, Daae and Boks (2017) held interviews and five workshops with experienced designers, who held at least a master's degree, to expand on their prior work. These events lasted for two hours and had from two to six participants, holding as the main goal of the exercise to collect empirical data. Data was later analyzed, and structured by the developers, the dimensions gathered from the studies became structured and clustered into dimensions, reducing the number of dimensions to 9 from the 55 initially collected themes. After several iterations, the tool took the form of a set of cards (see Figure 12). This project addresses the latest design available at the time of the completion of this thesis. The version of the tool published in 2017 is in the book Design for Behaviour Change: Theories and Practices of Designing for Change. Furthermore, the resulting dimensions are: control, obtrusiveness, encouragement, meaning, direction, empathy, importance, timing, and exposure. Each of these dimensions consider a 
spectrum that will be addressed in detail below. It is imperative to address the shared similarities with Froehlich’s (2011) Eight Dimensions of The Eco-Feedback Design Space, regarding the configuration and categorization of the dimensions and sliders. Such similarities provide a window to observe the transferability between HCI and design. Another important similarity can be observed in the format of the medium. This time, referring to Lockton's (2013) DwI cards, Boks, acknowledges the source inspiration. However, the design rationale is compared and discussed later in this thesis. 


\section{INFORMATION ACCESS}

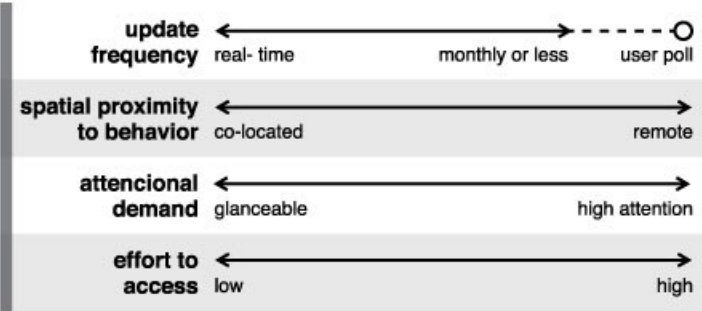

\section{INTERACTIVITY}

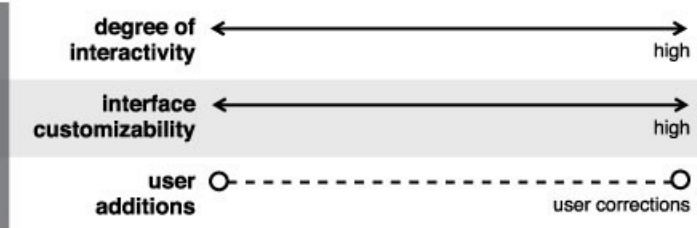

\section{Display Medium}

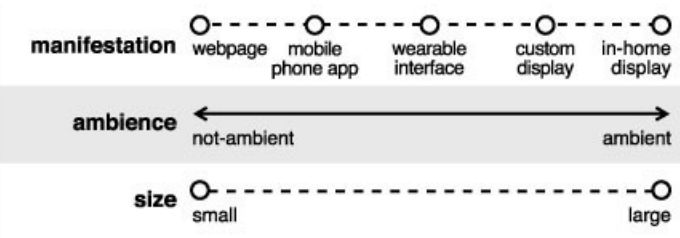

\section{ActionabiLITY / UTILITY}

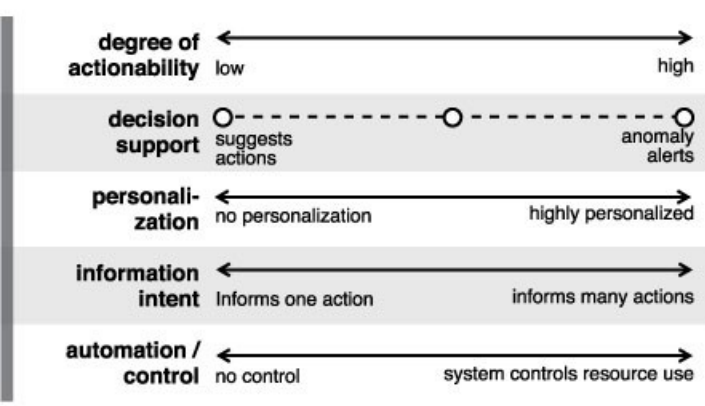

\section{Motivational / Persuasive Strategies}

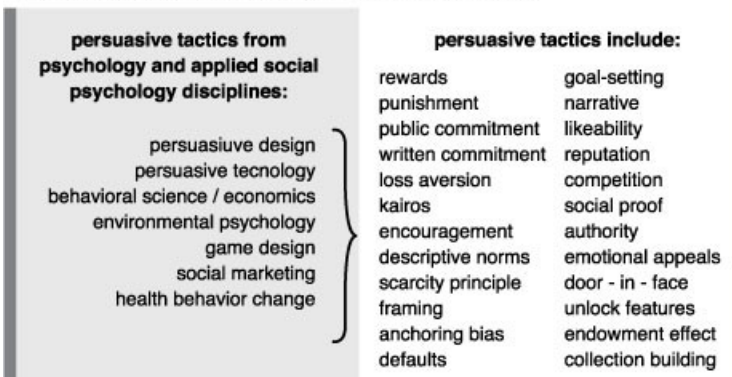

\section{Data Representation}

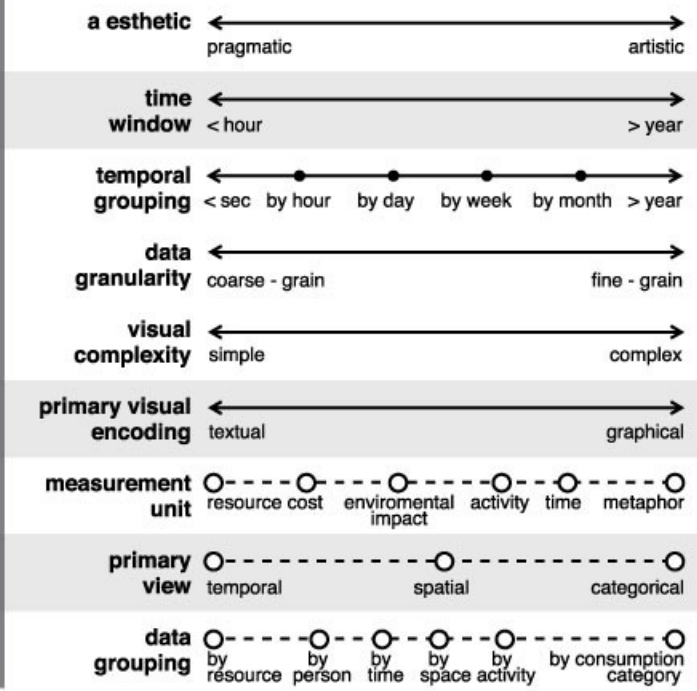

\section{Social Aspects}

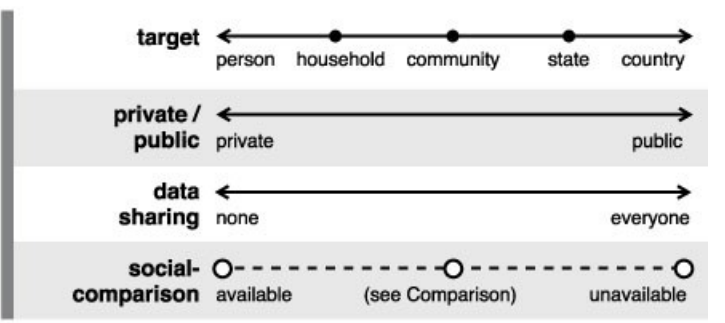

\section{Comparison}

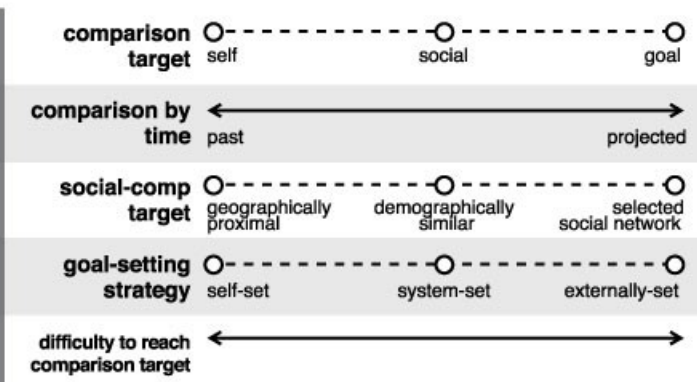

\section{comparison variable statistic computacion}

\begin{tabular}{|c|c|c|}
\hline $\begin{array}{l}\square \text { time window } \\
\square \text { time granularity } \\
\square \text { data grouping } \\
\square \text { data granularity } \\
\square \text { measurement unit }\end{array}$ & $\begin{array}{l}\text { O raw value } \\
\text { O average } \\
\text { O median } \\
\text { O mode } \\
\text { O other }\end{array}$ & $\begin{array}{l}\text { @ this time [yest, last wk, mo, yr] } \\
\text { [hrly, daily, wkly, monthly, yrly] } \\
\text { over past [X] days } \\
\text { this day type [weekday, weekend] } \\
\text { this day ofweek (e.g., mondays) }\end{array}$ \\
\hline
\end{tabular}

Figure 11. Depiction of The Eight Dimensions of the Eco-Feedback Design Space. Froehlich, 2011. 

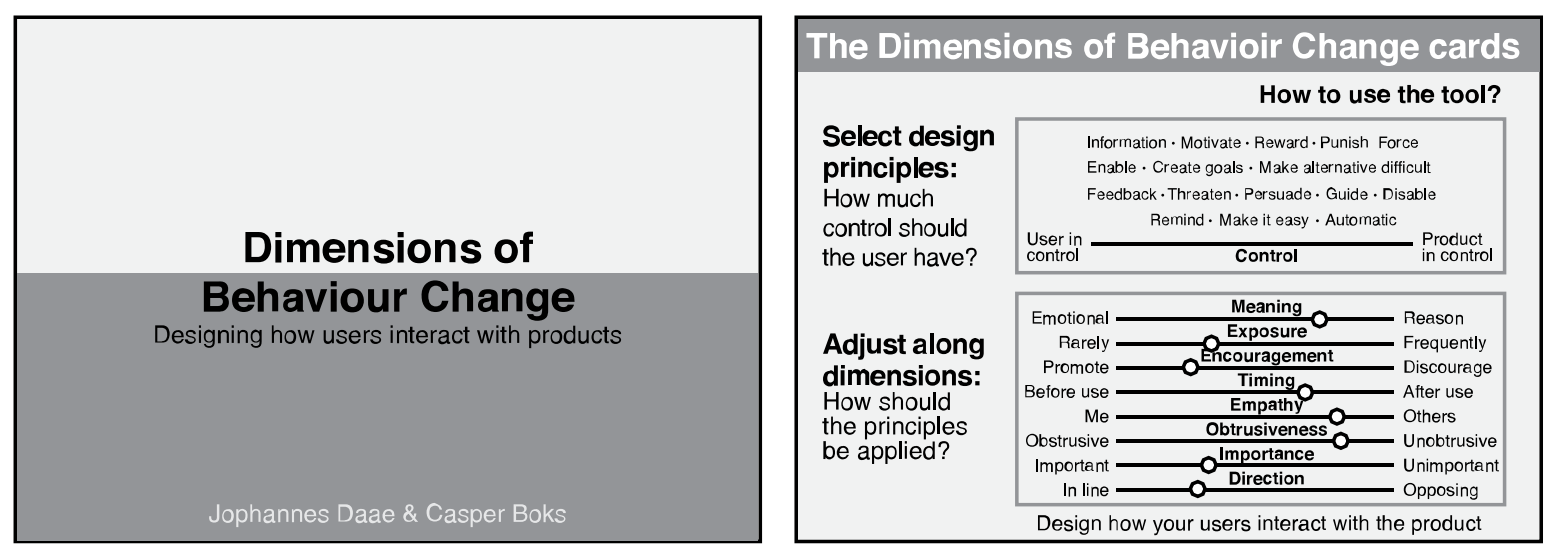

Figure 12. Depiction of Dimensions of Behaviour Change. Boks and Daae, 2013.

\subsubsection{SUMMARY AND CONCLUSIONS}

This section has presented a brief overview of some of the most discussed efforts in design for behaviour change. The author has approached a set of models, strategies, and tools, that aim to aid design in different levels, ranging from practice to theory in the efforts of understanding design and behaviour and their incorporation into practical applications. As it is mentioned above, some efforts build on existing theories from social sciences. Some researchers are more concerned with practical approaches and thus, aim at uncovering methods to empower designers with tools in the design for behaviour field. The literature review allows us to draw some important conclusions; but first, it would recognize the growing importance of the field, as the author advances in the review. The evolution of the field becomes evident, with increasing attention drawn to the field. Secondly, it is important to recognize that the field has been growing in a quasi-loose manner. By this, the author intends to address the lack of established processes and metrics to measure models. This is in part due to the recent emergence of the field. In this view, they are work of two recent 
important ventures that manage to structure the overall proceedings in the field. Niedderer et al. in Design for Behaviour Change: Full Project Report (2014) achieved the first global report that may be used as a reference to gain a comprehensive perspective with more rich detail of the field. Their work has helped to concentrate efforts in a single document and is a step in the right direction to give a more defined structure to the field in the future.

Additionally, the third gap is the lack of orderly methods for data collection. A progress in this area can be observed in Niedderer et al. (2016), as they describe in detail the methodology employed for data-gathering.

Before continuing with the following section that describes our approach, it is acknowledged that this section demonstrates the field is gaining valued attention not only in academia but public, and private sectors as well (Niedderer et al., 2016; Pettersen, 2013). Efforts aimed at formalizing methodologies, and processes are being undertaken. However, studies must continue to thrive as they are key vehicles in generating and disseminating knowledge.

\subsection{OUR APPROACH}

This study focuses on expanding the existing research in the DBC field, looking specifically at the incorporation of the Dimensions of Behaviour Change tool into practice. Previously, the literature review has laid the foundation for the main argument of this thesis, our discussion revolves around our main question, To what extent, can Dimensions of Behaviour Change tool- DBC model- be used in design practice to generate solutions that foster recycling behaviour within circular economy framework? To answer this question, our study 
is divided into two main arguments: the stakeholders and a new iteration of the tool. Before addressing these two arguments, the researcher sets out to outline the rationale to support the selection of the Dimensions of Behaviour Change as our subject of study.

As reported in the summary of the literature, the existing interest from public and private sectors regarding the behaviour change field, are more inclined towards tools that would enable practitioners to be better informed than on theoretical models (Niedderer et al. 2016). Although, it may argued that the sample of the study may not be representative, it is large enough to suggest more attention to this particular point. The level of complexity of theoretical models demands a richer knowledge of the field. Also, theoretical models require a structured methodology to properly contribute to the development of sound models. Drawing on the Niedderer et al. (2016) study, and the intentions of Lockton, Daae, and Boks, that the goal of their tools is to aid praxis, underpins our decision to choose the public and private sectors as the stakeholders of the tool.

The decision to select one toolkit over the other is grounded on two main factors; as it is stated before, more recent studies denote an inclination for tools over models from practitioners (Niedderer et al., 2016). Following this premise, the focus now addresses the DBC tool, and this framework offers a less complex landscape. Furthermore, when compared to the DwI, the DBC tool has suffered less cycles of redesigns, and testing (Lockton, 2013, Daae and Boks, 2017). Also, rather than taking a reducing or simplifying approach, more add-ons get incorporated to the DwI method: posters, website, diagrams, and user archetypes 
(pinball, shortcut, and thoughtful). Additionally, the dual modality of the tool- inspiration and prescription - and, ultimately, the main objective of the tool, which is to foster creative solutions in designers, is a complicated topic to address and measure. The sum of these factors makes it a much more complex candidate for the study. Whereas the DBC tool sets out to accomplish one specific goal, to aid designers make informed decisions about the strategies to take when tackling behaviour change challenges, (Daae and Boks, 2017), after having described the rationale of tool selection, the author now elaborates on the reason for a redesign.

In order to move onto the main argument, which focuses on the design decisions of the DBC tool, it must be noted that a significant factor over the performance of the tool is embedded in the very design of the tool, which has been limitedly addressed. As reported by Lockton (2013), he collected feedback on the design of the tool during the workshops. However, a structured study of the design of the tool is lacking. Furthermore, as the workshops continued to progress, Lockton (2013) incorporates more elements into the DwI method, in an attempt to attend the collected insights, posters, website, and new size cards. These changes do not follow a methodologically order, and by not isolating the changes it becomes more difficult to identify the positive or negative changes in the tool.

With the intent to provide an overview of the design framework of the DBC tool, the author starts by approaching the design guidelines, developed for the resulting tool by Daae and Boks (2014), and summarized in Boks' (2014) thesis as follows: 
- Be easy to adopt and implement.

- Facilitate designers to fulfil specified requirements.

- Reduce the risk that important elements in the product development phase are forgotten.

- Reduce the total calendar time to solve the task.

- Combine guidance, information, and education.

- Contain numerous examples.

- Be as visual as possible and contain a minimum of text. When text is needed, it should be written in a non-scientific language.

- Be referred to when required and fit into the designers' usual way of working.

- Focus on design.

Boks (2014), notes the little literature available to structure the dimensions, and tackles this by building on prior work (Lockton, 2013) readily available in the reviewed literature.

Discussion leans to support a physical format over a digital one, based on the arguments of feasibility and reliability of the medium in workshops as Boks suggests (2014, p. 163).

Having established the medium for the tool, Boks then selects the format, picking an A5 card size (148 X 210mm) based on reports by Lockton (2013), who suggests a smaller size would only be useful for individual interactions and might not be suited for group presentations, which is one of the main activities during the workshops, as Lockton reports. It is important to stress that Lockton's DwI (2013) has a different purpose regardless of the similarities in both toolkits. As Daae and Boks claim (2017, unpaged.) DwI "aims to help 
designers generate as many ideas as possible for changing behaviour through their design, whereas DBC aims to help designers make informed decisions about which strategies may be most suitable in relation to a certain design for sustainable behavior challenge”. This slight, but important difference must be informing the resulting tool. Our argument regarding the design of the tool, starts by highlighting the interdisciplinarity of the field, evident across the literature. Originally borrowing from social sciences- psychology and sociology- Design for Behaviour Change is a field that thrives on multiple disciplinary perspectives, building on this view, attention now shifts towards the design principles that shaped the tool. If we are to change the result, we must approach the task under a different lens, so far the literature frames the tools as cards and posters. However, the argument this thesis poses is that the cards are the interface between the user and the tool. This notion is not new; in fact, it is mentioned in Lockton's PhD thesis (2013). However, Daae and Boks focus on other aspects of the tool.

To summarize, our approach to the research question: To what extent can Dimensions of Behaviour Change tool be used to inform design practice to generate solutions that foster recycling behaviour within circular economy framework? The answer to this question is twofold. Firstly, based on the argument we presented above; we will redesign the tool drawing on HCI design principles. The details will be described in the methodology section. Secondly, we will design a study to collect insights in both forms- qualitative and quantitative- to then analyze the results and formulate an answer to our question. 


\section{METHODS}

This section describes the design research methods of our project, aiming to inform the following study design. The arguments presented below draw on a rationale informed and supported by previous studies, that ultimately, strive to contribute to form a more detailed perspective for future efforts. In this view, methods that support collecting insights about the user are selected.

Research stances, according to the categories developed by Frayling (1993) - research for design, research through design, and research about design - vary in relation to the intended output and the utilized means to produce knowledge. Our study aligns with research through design (Frayling, 1993) description, the project contributes to an iterative process in the development of a design tool. The elaboration of an artifact as medium to collect data and undertake the study fits in this category, as Pontis (2010) puts it, "research through design involves both understanding the process of design itself and developing new design actions, artefacts or methods". Compared to research for design "the development of new artefacts of which the goal is to visually communicate new knowledge." (Pontis, 2010). It is then assumed, to some degree, this project also fits in the research for design category, based on the intention to provide knowledge that would conclusively serve practice. Furthermore, according to Robson (2002), research motivations may be explanatory to describe a particular event or situation, be descriptive to explain a given situation or problem, or be exploratory to investigate an emergent issue. Similarly, Graziano and Raulin (2004) who 
suggest an exploratory approach is more productive in the early stages of a research topic. Therefore, it is stablished that the motivation of this research is exploratory.

It is important to mention that design research draws on a varied range of traditions, such as those within art schools, engineering schools, business schools, psychology, among others. This rich background favors the size of the collection methods, upon which design research may lean on. However, it also makes it difficult to delimit the boundaries of what design methodology conforms to in an academic sense (Kimbell, 2011).

After outlining the research approach above and having stressed the value of considering qualitative and quantitative methods, both types of research are described below, and then the selected set of instruments for this study is presented.

To answer our research question, it is important to access user's feedback on the DBC tool, since it would help to learn how it may be improved to be effectively incorporated into praxis. Drawing on prior studies in the field (Niedderer et al., 2016; Lilley, 2006; Boks, 2010; Elias, 2008; and Wever, 2010), the set of methods used to collect data varies. However, there are methods that coincide across the revised literature. Since the author follows the methods outlined by Daae (2014), Daae and Boks (2014), it is suggested to collect qualitative data in the form of workshops, combined with interviews of experts, to gain an understanding of the practical potential and limits of the tool. It is also noted in similar studies, the use of an evaluating instrument, (Lockton, 2013, Daae, 2014, and 
Niedderer et al., 2016). Before the author outlines our methods, first, it is provided a brief description of the two types of data this study aims to collect.

\subsection{THE QUALITATIVE ROUTE}

Qualitative research is described as the study of a specific phenomenon, issue, or problem, in a systematic and interpretative manner (May, 2001, McQueen and Knussen, 2002). It investigates phenomenon using non quantifiable data, and the data typically consists of words describing the phenomenon. (Golafshani, 2003). Such features render qualitative research a suited candidate for the exploratory purposes of this project. Additionally, it is supported by its reported use in prior studies in the field. Moreover, qualitative methodology determines that data derived from research studies be coded and clustered (Miles and Huberman, 1994) to conform to a "limited number of predetermined response categories to which number are assigned" (Patton, 2002). In order to determine "patterns and relationships that can generate theories and hypotheses", coded and emerging data are continuously compared in an iterative manner. (McQueen and Knussen, 2002, p. 200).

\subsection{A QUANTITATIVE COUNTERPART}

In contrast to qualitative methods, quantitative research aims to measure, count, and quantify parameters to deliver conclusive results (Golafshani, 2003). Furthermore, the most important difference resides in its foundation, since it builds on the notion that everything can be described according to a numerical system, (McQueen and Knussen, 2002). As mentioned above, a quantitative method is considered in this study to enrich the validity of 
the results, as it is suggested by Patton, (2002), and supported by Golafshani, (2003). One way of strengthening studies is to triangulate multiple methods.

\subsection{SYSTEM USABILITY SCALE}

Our project strives to evaluate the tool based on the reason that a quantifiable method would serve two purposes: firstly, it would provide a measurable reference point about the user perception of the tool, and secondly, it will help triangulate the qualitative data. Measuring subjective elements such as experiences, is a challenging task to tackle. This challenge has been tackled and discussed in HCI research over decades. Arguments that support the reasons for evaluation varies, however, the primary reason is to influence the design of a product (Baber, 2005).

Efforts in HCI to measure usability of the systems bloomed in the 1980's resulting in a wide variety of tools. Before embarking on the description of the tools, we must first define usability in terms of HCI. Usability is an elusive term that may be defined according to different purposes, due in large part to its multidisciplinary origin (Baber, 2005). Although, the author recognizes its ambiguity, this work does not intend to contribute to it, and rather focuses to builds on Shackel's (1984) usability definition: "the capability in human functional terms (of a product) to be used easily and effectively by the range of users, given specified training and user support, to fulfill the specified range of tasks, within the specified range of environmental scenarios". To measure this concept, tools have been developed 
according to different needs. However, this project focuses on the System Usability Scale developed by Brooke (1996).

These tools lean on different parameters to define the usability of a given system. Some, measure effectiveness, efficiency, and satisfaction. However, according to Lewis, (2018), the System Usability Scale- SUS - is acknowledged to be used widely to assess perceived usability on post-study questionnaires. As stated above, our project follows an exploratory approach, and aligns with a post-questionnaire structure, drawing on these features we have selected the SUS as the initial reference to measure the perception of the users regarding the tool.

The SUS is structured on a 10 question format that uses a Likert scale (see Figure 13). This means that the answers to the questions are represented with 5 different options in a scale with two extremes- strongly disagree, and strongly agree. According to Brooke, (1996, ND.) "to calculate the SUS score, first sum the score contributions from each item. Each item's score contribution will range from 0 to 4 . For items $1,3,5,7$, and 9 the score contribution is the scale position minus 1 . For items $2,4,6,8$ and 10 , the contribution is 5 minus the scale position. Multiply the sum of the scores by 2.5 to obtain the overall value of SU"(SU as per original quote). 
This approach although simplified, has been widely applied in HCI as it provides an overview that may be superficial. It offers a window to user's perceptions, that is reinforced when integrated or combined with other methods.

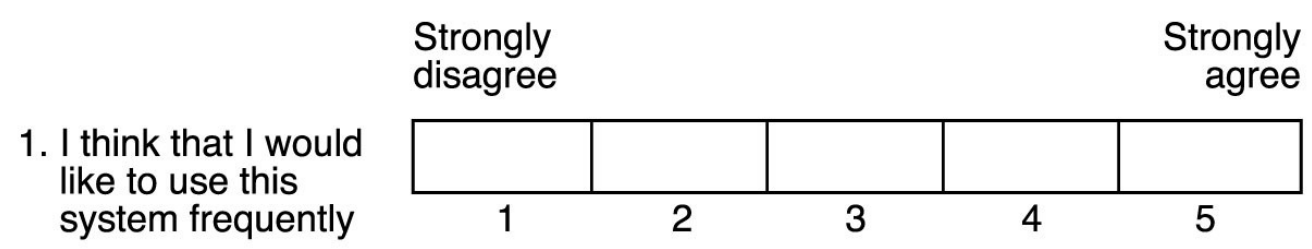

Figure 13. Likert Scale Example.

\subsection{REGROUPING, COVID-19}

The group of combined methods initially outlined- workshops, expert interviews, and online questionnaire- was intended to help triangulate the results in the following sections.

However, a series of unforeseen events at a global scale, affected the first approach. Covid-19 appeared in Canada in March 2020, altering the way social interactions take place. Such event demanded adjustments at all levels as we all have experienced them globally throughout 2020. Although the literature suggested workshops as the route to follow, the adjustments required for a change in the methodology. In this view, workshops were removed from the set of methods, reducing the data collection to two methods: system usability scale, and expert interviews.

Interviews are described as general techniques for acquiring input from the user, without any limitations to what the focus of the investigation is, rendering them suitable to provide information about individual actions, motivations, and reconstruction of decision-making 
processes (Aldersey-Williams et al., 1999). They can provide rich, detailed data, and give a broader view of the system (Courage and Baxter, 2005). Individual interviews are more suitable to investigate sensitive topics than methods involving more people (AlderseyWilliams et al., 1999). Experts interviews are often used in empirical research and are reported to contribute to practical aid and theoretical reflection (Bogner, et al., 2009). Furthermore, the type of interview selected for this study is semi-structured, which would have a deep discussion regarding behaviour and its relation to the tool, but at the same time, it will provide enough room to expand on details that may have been unforeseen by the researcher.

The use of survey and questionnaires in design research is consistent across the literature (Boks, 2010; Boks et al., 2015; Lockton, 2013; and Niedderer et al., 2016). Surveys or questionnaires are described as a set of questions that require answers directly, use of multiple-choice or rating based on a scale are also acknowledged (Preece et al., 2002, Courage and Baxter, 2005, Maguire, 2001). This method can shed light on information about the user's needs, requirements, and demographics (Courage and Baxter, 2005), as well as attitudes (Maguire, 2001). Similarly, leaning on Crotty's (1998) argument, that qualitative and quantitative types of research, their features are subjected to the mode of execution, rather than being a higher-level type of research; a survey can equally generate qualitative and quantitative data. In this view, this study develops a questionnaire aimed at collecting both types of data. 


\subsection{SUMMARY}

By following to some extent, preestablished processes, the methods appointed in this study are expert interviews, and a questionnaire that includes a form of the standard usability scale.

Overall, this study may be described as quantitative given the proportional ratio of qualitative methods chosen to expand the current scope of studies regarding the practical applicability of the DBC tool, which offers an opportunity to contribute to the Design for Behaviour Change field.

All in all, this section has described the research approach of this project: research for design and through design, the exploratory research motivation according to Robson's (2002) categories, and the methods selected to answer the research question; and it has described expert interviews, and online survey. 


\section{STUDY PROCEDURE}

This section presents a description of the project; it narrates the stages of the study in a descriptive manner: the participants, instruments for data collection, and the relationship between them. It aims to provide a detailed picture of the design of the study, considering the planning, instruments, and implementation before presenting the results of the gathered data.

\subsection{OUTLINE}

Developed in accordance with the selected methods: expert interviews, and questionnaires; this section describes the activities selected at the planning stage, that involve all the mentioned instruments.

\subsection{INTERVIEWS}

In order to provide consistency across the different meetings, sessions were carried out in a similar manner to every participant by adhering to the format presented below.

\subsubsection{SESSIONS OUTLINE}

Objective: Present recycling/design professionals the Dimensions of Behavior Change tool that aims to aid practitioners. The interview centers on the application of the Dimensions of Behavior Change tool, and its integration in the design process, followed by the collection of the participants feedback to ultimately, gain valued insights. 


\subsubsection{ACTIVITIES BREAKDOWN}

Presentation: Participants will receive a detailed presentation of the DBC tool and an outline of its incorporation in the design process ( 25 mins).

Feedback: After completing the presentation of the DBC tool, participants will be asked to complete an online questionnaire (10 mins).

Closure: Any additional comments or questions may be discussed before thanking the participants (10 mins).

\subsubsection{DATA GATHERING}

Data produced by the participants will be collected in the same manner during the interview, and such data that will be collected in three complementary forms:

- Observational notes made by the principal investigator during and after the interview.

- Screenshots of the participants during the sessions.

- Online questionnaires at the end of the session.

\subsection{PARTICIPANTS}

Drawing on the literature, we identify private and public sectors as the two main pillars suggested for incorporating Design for Behaviour Change proceedings (Boks et al., 2015; Lockton, 2013; Niedderer et al., 2014; Niedderer et al., 2016; Pettersen, 2013); the existing feedback from public and private sectors suggest an important interest in the development of 
tools in the DBC field, combined with the intend of researchers who aim to incorporate proceedings into practice, sets the ground for the outline of the participants.

As previously stated, most of the existing studies of the DBC tool have involved students (Lockton, 2013; Daae and Boks, 2011). Only one of the early attempts describes the participation of practitioners with master's degrees (Boks, 2014). However, this attempt utilized the previous version of the tool- design principles- to collect data that would later help formulate the dimensions, and not the DBC tool. Following the existing stream in the field (Niedderer et al., 2016), that aims at gaining more insights from the private and public sectors, it can be inferred from this view that there is where the intended user of the tool(s) resides. And, thus, participants for this study are be described as experienced professionals in the private and public sectors: including planners, coordinators, waste management managers, and communication experts from the public sector (with similar participants from the private sector, such as senior UX designers, design researchers, service designers, and strategists recruited as part of this project).

Sample size is a challenging factor to determine in research, as there are different perspectives that describe the best approach according to the project. However, this thesis does not engaged in that debate and rather acknowledges the existence of it. The sampling method is in function of the high level of experience and availability of participants who match the criteria described above. This study used a snowball sampling approach, and its purpose is described by Hignett (2005, p. 121) as "identifies cases of interest from people who know 
people, who know what cases are information-rich, i.e., good examples for study." Our initial sample size of 10 participants was determined based on the studies conducted by Boks et al., (2015) and Niedderer et al. (2016).

\subsection{INSTRUMENTS}

This section covers the design part of the study, design in the sense of planning the activities, and of producing the instruments. The section focuses on the first phase of the answer to our research question, to highlight the stance of a research through design. This phase describes the gap about the design of the tool identified in the literature. Advocating on the multidisciplinary origin of the field, this iteration of the tool leans on HCI design principles, approaching the resulting artifact that conforms the DBC tool, as an interface between the user and the knowledge embedded in the tool.

Human-Computer Interaction (HCI), also deemed Software Psychology, is a field that emerged as a field in the 1970s, at the intersection of computer science and psychology. The purpose of the field was to develop and evaluate applications of technology, illustrating the possibilities to psychology as a design science (Carroll, 1997). Its progress has suffered major changes, like other disciplines; new approaches, models, methods, and strategies shape the field. This resulted in a wide variety of applications that range from interfaces in airplanes control to web design. Some of the most important proceedings that relate to the work of this thesis, are Nielsen's (1994) heuristics, which are used as guidelines in the iteration of the DBC tool created in this thesis. Nielsen principles for interaction design, were first 
introduced by Nielsen and Molich (1990), and developed in an effort to make the existing

guidelines easier to understand by developers. Refined through decades of iterations,

Nielsen's heuristics are reported to be a useful tool in HCI, table 1 lists and describes the

heuristics.

Table 1. Nielsen Heuristics.

Nielsen Heuristics

\begin{tabular}{ll}
\hline Heuristic & Description \\
\hline Visibility of system status & $\begin{array}{l}\text { The system should always keep users informed } \\
\text { about what is going on, through appropriate feedback } \\
\text { within reasonable time. }\end{array}$ \\
\hline $\begin{array}{l}\text { Match between system and the real } \\
\text { world }\end{array}$ & $\begin{array}{l}\text { The system should speak the users' language, with } \\
\text { words, phrases, and concepts familiar to the user, } \\
\text { rather than system-oriented terms. Follow real-world } \\
\text { conventions, making information appear in a natural } \\
\text { and logical order. }\end{array}$ \\
\hline Users often choose system functions by mistake and \\
will need a clearly marked "emergency exit" to leave \\
the unwanted state without having to go through an \\
extended dialogue. Support undo and redo.
\end{tabular}


provide help and documentation. Any such

information should be easy to search, focused on the user's task, list concrete steps to be carried out, and not be too large.

\subsection{DESIGNING THE TOOL}

Following our discussion regarding the design of the DBC tool, this section presents the principles used to develop a further iteration based on the $5^{\text {th }}$ of the DBC tool (see Figure 14), as presented in Daae's thesis (2014). It is important to illustrate a continuum of the steps along the development of the tool. The departing point is the existing version of the Dimensions of Behaviour Change tool shown in Figure 13. The steps involved in the new design start by identifying the existing elements in the tool:

- Dimensions named at the top corner divided into two extremes.

- Principles distributed along the spectrum.

- Examples in the form of photographs.

- Spectrum of the dimensions shown with two arrows on the opposing ends.

- Tips, that show possible positive and negative outcomes according to their position on the spectrum.

- Colors consistent across (almost) all the dimensions.

- Typography visible throughout the cards. 

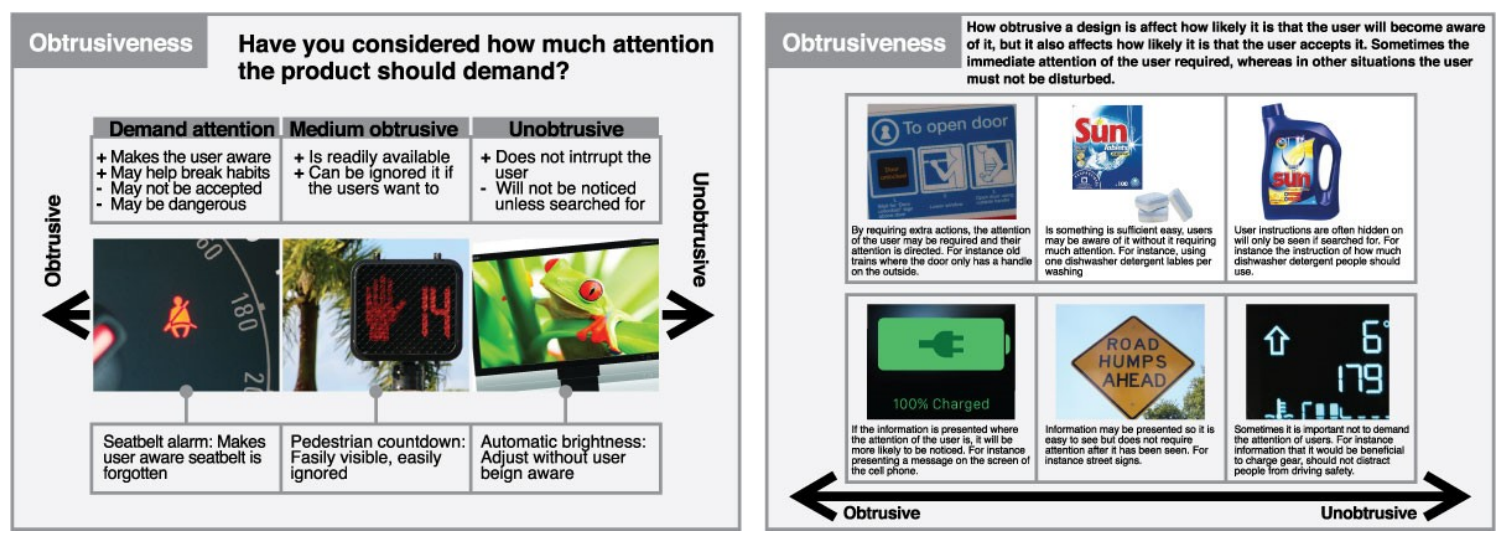

Figure 14. Depiction of Dimension of Behaviour Change - Obtrusiveness Card. Daae, 2013.

After a visual analysis, a summary of the identified opportunity areas of the design according to a minimalist approach based on information design is as follows. Text content is

abundant, it is unclear which of the sides conforms the front or back as they both include

similar content. Information is constantly repeated across the medium. The use of

photographs makes visual consistency challenging, some examples use the same image which may result difficult to interpret to the user.

Once the structure of the tool was broken down into its essential components- dimensions, spectrum, principles, examples, benefits, and disadvantages- the next step was to define the information architecture. The concentrated content of the tool is presented in table 1 , all the information is rephrased from Daae and Boks (2017). The methodological approach to the design of the tool, is informed in great part from the HCI methodological design process, that aims to address individual aspects of the design at the time. 
Table 2. Information Taxonomy of the DBC tool.

Information taxonomy.

\begin{tabular}{|c|c|c|c|}
\hline DIMENSION & DESCRIPTION & SPECTRUM & PRINCIPLE \\
\hline Control & $\begin{array}{l}\text { Considered the master dimension, } \\
\text { describes the allocation of control } \\
\text { between two extremes-user and } \\
\text { product-according to the axis } \\
\text { developed by Lilley. }\end{array}$ & $\begin{array}{l}\text { User } \\
\text { Product }\end{array}$ & $\begin{array}{l}\text { Depending on the } \\
\text { position of the intend } \\
\text { along the spectrum, } \\
\text { principles would } \\
\text { describe strategies } \\
\text { accordingly. }\end{array}$ \\
\hline Obtrusiveness & $\begin{array}{l}\text { Refers to the level of attention } \\
\text { demanded from the user. The } \\
\text { spectrum ranges of two opposed } \\
\text { extremes Obtrusive and Unobtrusive. } \\
\text { This dimension also impacts the } \\
\text { likeliness of a user adopting a new } \\
\text { behaviour. }\end{array}$ & $\begin{array}{l}\text { Obtrusive } \\
\text { Unobtrusive }\end{array}$ & $\begin{array}{l}\text { According to the } \\
\text { selected approach. } \\
\text { Obtrusive would place } \\
\text { information more visibly } \\
\text { to make users aware. } \\
\text { Unobtrusive would do } \\
\text { the opposed. }\end{array}$ \\
\hline Encouragement & $\begin{array}{l}\text { This dimension describes the two } \\
\text { extremes that would motivate or deter } \\
\text { behaviours. It refers to promoting and } \\
\text { discouraging. }\end{array}$ & $\begin{array}{l}\text { Promote } \\
\text { Discourage }\end{array}$ & $\begin{array}{l}\text { Strategies are } \\
\text { presented according to } \\
\text { the location of the } \\
\text { spectrum. Remove or } \\
\text { increase barriers to } \\
\text { promote or discourage } \\
\text { behaviour. }\end{array}$ \\
\hline Meaning & $\begin{array}{l}\text { Refers to the affective aspect of } \\
\text { artifacts. This dimension considers } \\
\text { the reason and emotion as opposed } \\
\text { extremes. }\end{array}$ & $\begin{array}{l}\text { Reason } \\
\text { Emotional }\end{array}$ & $\begin{array}{l}\text { Affective design has } \\
\text { been discussed on } \\
\text { other articles as a } \\
\text { possible actor in the } \\
\text { incorporation of } \\
\text { environmentally inclined } \\
\text { attitudes. }\end{array}$ \\
\hline Direction & $\begin{array}{l}\text { In function to a previously defined } \\
\text { behaviour. If the behaviour of the } \\
\text { user is aligned to the prescribed } \\
\text { behaviour, it is then in-line, otherwise } \\
\text { it moves towards the opposed end of } \\
\text { the spectrum. }\end{array}$ & $\begin{array}{l}\text { In line } \\
\text { Opposed }\end{array}$ & $\begin{array}{l}\text { Behaviours in line to } \\
\text { prescribed goals, may } \\
\text { be enabled by } \\
\text { eliminating barriers, or } \\
\text { reducing steps. Those } \\
\text { opposed to the desired } \\
\text { shall encounter } \\
\text { obstacles and/or } \\
\text { blockages. }\end{array}$ \\
\hline Empathy & $\begin{array}{l}\text { This dimension describes the } \\
\text { different levels that may be triggered } \\
\text { in a user regarding individual or } \\
\text { community inclinations. }\end{array}$ & $\begin{array}{l}\text { Me } \\
\text { Others }\end{array}$ & $\begin{array}{l}\text { Gains aimed at } \\
\text { promoting behaviours } \\
\text { shall be outlined } \\
\text { according to the user's } \\
\text { empathy profile. Self- } \\
\text { centered users align } \\
\text { better with individual } \\
\text { gains, as opposed to } \\
\text { community-inclined } \\
\text { users. }\end{array}$ \\
\hline Importance & $\begin{array}{l}\text { Information vary in the level of } \\
\text { importance. Ranging from critical to }\end{array}$ & $\begin{array}{l}\text { Important } \\
\text { Unimportant }\end{array}$ & $\begin{array}{l}\text { Critical information shall } \\
\text { draw user's attention to } \\
\text { ensure its delivery. }\end{array}$ \\
\hline
\end{tabular}




\begin{tabular}{|c|c|c|c|}
\hline & $\begin{array}{l}\text { trivial, information should be } \\
\text { categorized accordingly. }\end{array}$ & & $\begin{array}{l}\text { Trivial information may } \\
\text { not obstruct the } \\
\text { completion of tasks. }\end{array}$ \\
\hline Timing & $\begin{array}{l}\text { The timing spectrum speaks to the } \\
\text { different moments in which } \\
\text { interactions with the user may take } \\
\text { place. }\end{array}$ & $\begin{array}{l}\text { Before } \\
\text { During } \\
\text { After }\end{array}$ & $\begin{array}{l}\text { Priming user's actions } \\
\text { happens before } \\
\text { interactions take place. } \\
\text { Engaging with the users } \\
\text { during the time of the } \\
\text { interactions help to be } \\
\text { present and not annoy } \\
\text { the user. Follow-up } \\
\text { method may be } \\
\text { preferred by some } \\
\text { users. }\end{array}$ \\
\hline Exposure & $\begin{array}{l}\text { This dimension outlines the } \\
\text { occurrence of events (messages, } \\
\text { tasks, communication). Priming, } \\
\text { informing, and follow-up } \\
\text { communications with users may } \\
\text { adhere to a balanced approach that } \\
\text { fosters positive desired behaviours } \\
\text { without being invasive. }\end{array}$ & $\begin{array}{l}\text { Frequently } \\
\text { Rarely }\end{array}$ & $\begin{array}{l}\text { If the frequency is high, } \\
\text { users may be more } \\
\text { inclined to adopt a } \\
\text { prescribed behaviour, } \\
\text { however, it may also be } \\
\text { perceived as invasive. } \\
\text { Finding a balance is } \\
\text { important to stablish a } \\
\text { healthy relation. }\end{array}$ \\
\hline
\end{tabular}

Initially planned, an individual-use approach on the design of the cards, along with the testing of the digital version of the tool was the overly ambitious scope of the project.

Unfortunately, given the project constraints such as time, artifacts, technical skills, and funding, future efforts may pick up the work done and continue to fulfill the wholesome, yet challenging development of an app. This iteration aims to represent a step towards a digital direction of the tool.

Continuing the individual-use approach, the selected format was based on a paperprototyping size. The tool is comprised of two sides - front and back - visibly different, with the information contained in a $7 \times 12 \mathrm{~cm}$ sized card. The selection of this size is based on the amount of information that is capable of contain in the context of individual user. 
Notable changes were made during this phase based on the literature, first, it has been reported by Lockton (2013) and Daae (2014), that there needs to be a well-defined user to match with the principles. This notion is discussed throughout the literature, focusing on Lockton (2013), Coskun, and Erbug, (2014), and Daae and Boks (2017). The need of previously defined users is widely recognized. Lockton addresses this concern more directly by developing and incorporating the framework- Pinball, Shortcut, Thoughtful- which is intended to be used in conjunction with the DwI method. Following these arguments, a segment of the tool is added to include user's profiles (personas or archetypes). Additionally, as reported by Daae and Boks (2014), the priming effect of the examples in participants during the workshop, leads to the decision of removing this feature from the iteration of this toolkit. The resulting design of the tool is presented below (see Figure 15) followed by a description of the design decisions. 

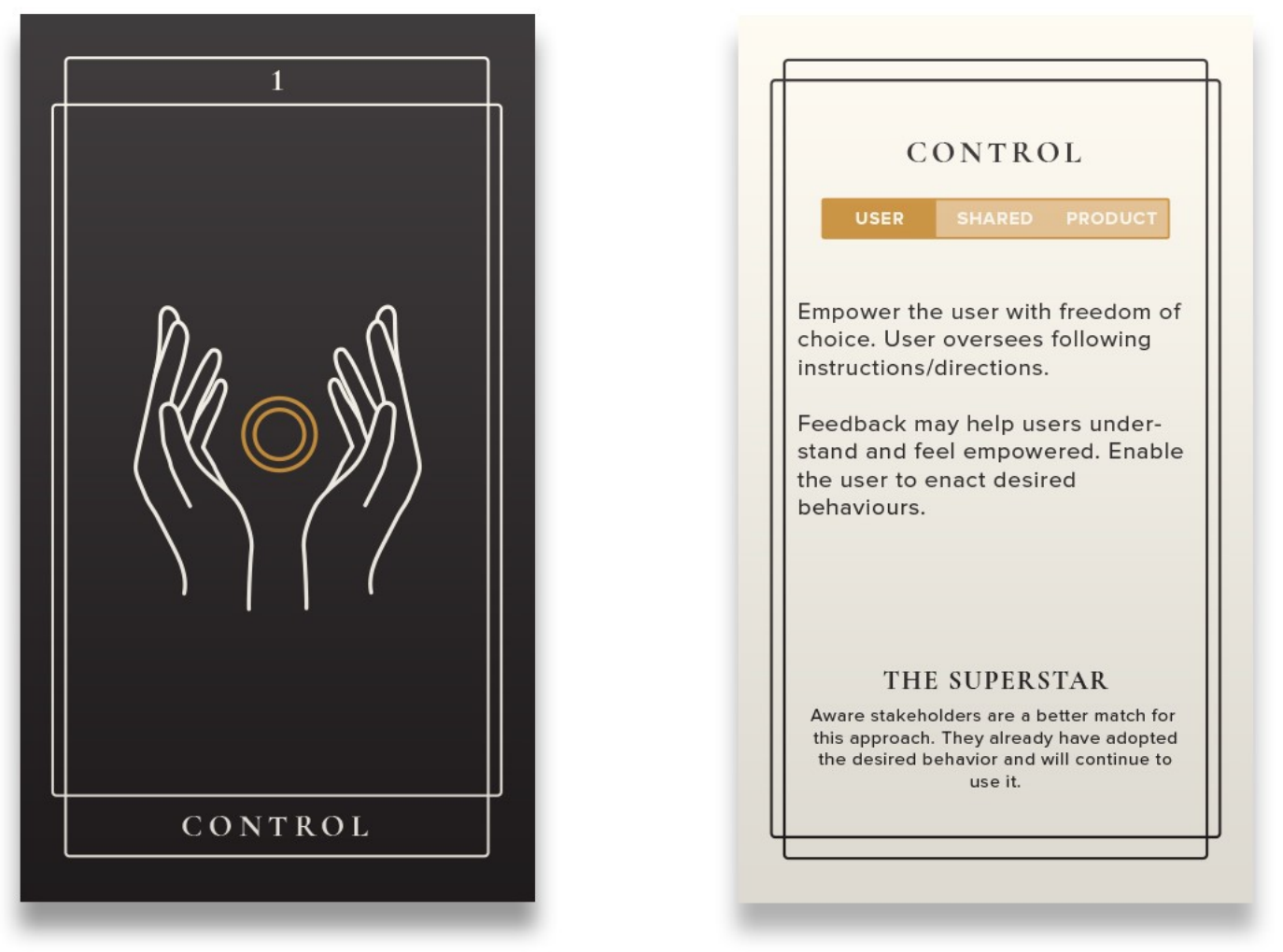

Figure 15. DBC Tool Control Card Sample.

The resulting iteration is comprised of two sides, front and back. The front contains three elements: header, pictogram, and footer. The header shows the number of the dimension according to the order listed by Daae. In the middle we can find the pictogram, the intention of the pictogram is to aid the user to have a better recall by identifying a graphical element. At the bottom, the name of the dimension of the card is included. The overall objective of the front of the cards is to help the identification and navigation of the cards in a physical form. Conversely, the back of the cards contains the most important information of the tool. It is conformed of four elements, header, spectrum slider, principle, and archetype.

Significant changes take place in both. The information now includes a user archetype, and the slider has been replaced for a segmented spectrum. These changes will be described in 
detail below, but first, the header and principles are described. The header shows the name of the dimension, it is intended to help the user with the information at hand in both sides of the card.

Design changes are addressed based on the order of appearance on the card. First, the adoption of a spectrum that has specific segments draws on best practices in user interfaceUI- design, as reported by Nielsen Norman Group website (2017), reporting that the use of linear sliders is used for highly customizable values. In this case, the approach presented by Zachrisson et al. (2010) in Figure 3, offers a more specific location along the spectrum. Drawing on the reductive approach of this iteration, the spectrum of the dimensions has been reduced to three categories, with the intention to provide the stakeholders clear information about the position of the approach and the principles.

\subsection{ARCHETYPES, PERSONAS, AND USERS}

In every design project, design is intended with some model of user in mind. As Lockton, et al. (2012, p. 12) report, "in designing to influence user behaviour, this potentially becomes even more important to consider.”. It is then important to incorporate this information in the cards, expanding the argument to support this feature. Coskun, and Erbug, (2014), highlight the importance of considering a diversity of users when designing in the behaviour change field. This suggestion is mainly supported by the different attitudes, beliefs, motivators, etc. that may influence the resulting response. On the other hand, modeling users is a field of its own. One of the most used tools in design to understand users is 
personas. They are used in two different ways; they communicate in a familiar manner who the user is and can provide a quick introduction rich in details to an abstract user. Personas are developed on rich data and are useful in communicating needs and attitudes (Holtzblatt, and Beyer, 2016). Conversely, the use of personas has suffered some critiques in design. Most of these arguments draw on the overuse and shallow approaches to personas.

Regardless, in the literature it is agreed that there is a need of a rich user research. Following this stream, the cards incorporate a customizable space for the inclusion of users, whether in the form of personas or archetypes, and the space is destined to allow stakeholders to connect prior developed user profiles with the principle on the card.

Fortunately, when reaching out to the public sector participants, they informed us of an ongoing project that aligns in large part to ours. Qualitative and quantitative research was already developed around the users in the City of Ottawa, learning about their attitudes, motivations, barriers, and behaviours to overcome. Drawing on this document, this study was very well informed about the users, which resulted in an iteration that contains current data to work with.

Elaborating on this vein, according to the literature it is evident that performance of the tool is directly impacted on the amount of information about the user (Lockton, D., Harrison, D., and Stanton, 2012; Lockton, 2013; Coskun and Erbug, 2014a; Coskun and Erbug, 2014b; Daae and Boks, 2017); in other words, the better we know our user(s) - attitudes, behaviour, barriers, motivations, demographics, etc.- the better the strategy can perform. 
Drawing on this acknowledgment, the study proposes a framework presented in Figure 16. Our model is aimed at connecting two stages of the design process- research and ideationin a more concise manner. Although, the model is based on a linear approach, an iterative framework may be worth exploring as well.

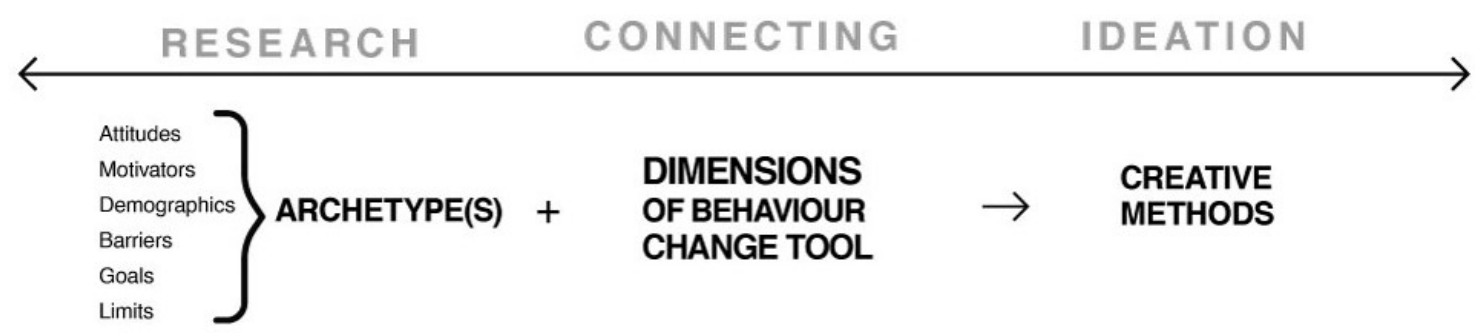

Figure 16. Model for Incorporating Dimensions of Behaviour Change.

\subsection{QUESTIONNAIRE}

As described above, questionnaires are flexible instruments in regard of the type of data they can include. This view resulted in the development of a hybrid (see Figure 17) questionnaire that would enable the collection of both qualitative and quantitative data. Questions that would enrich the study with information from the participants, such as the level of knowledge regarding the behaviour field, and the years of professional experience are incorporated in the questionnaire. Conversely, eight questions to gather quantitative data in relation to the usability of the tool form the majority of the questionnaire. 


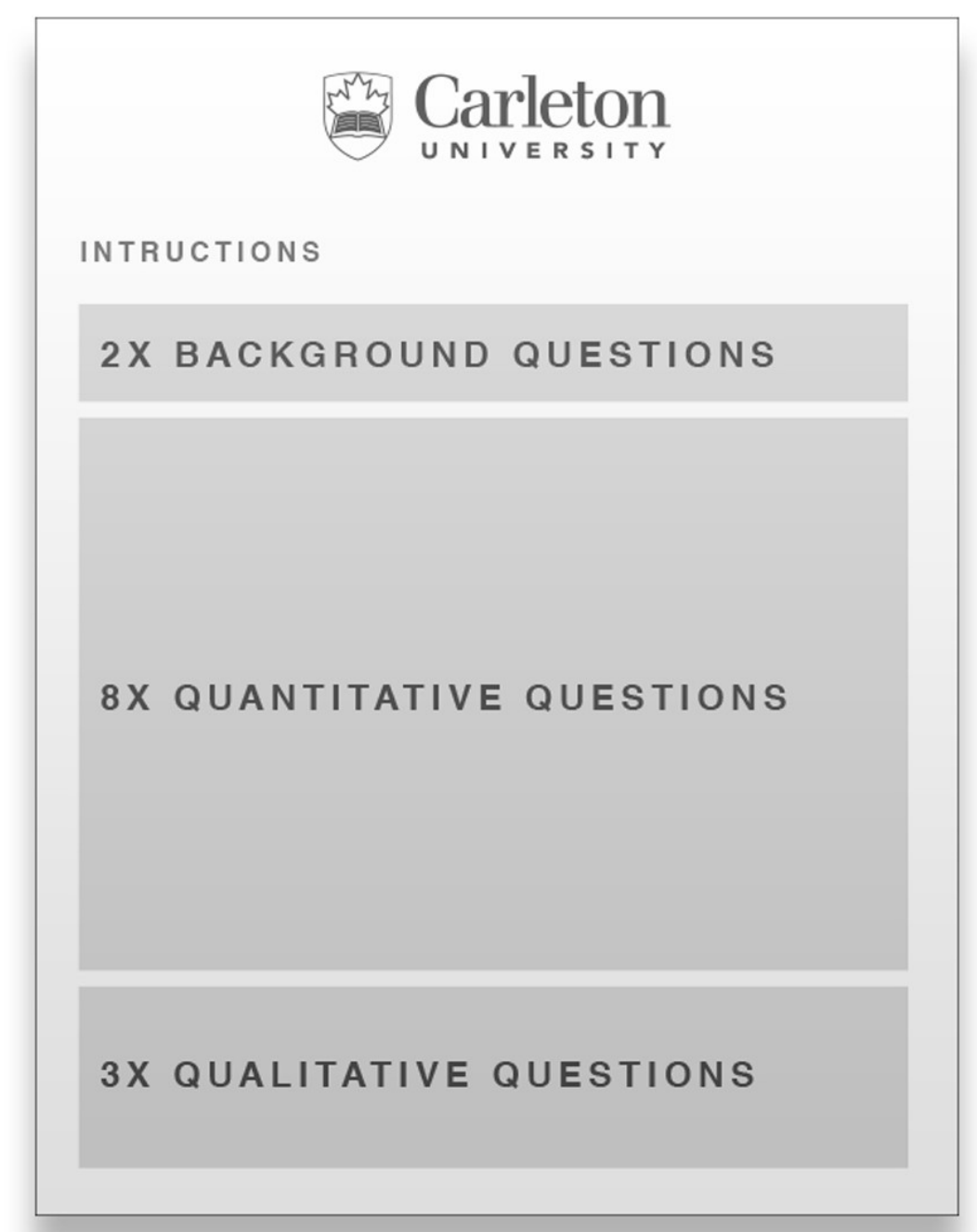

Figure 17. Questionnaire Taxonomy.

\subsection{PROCEDURES}

According to Covid-19 guidelines, the entire study was carried out in a virtual manner;

participants who met the criteria described above, were recruited via email following a snowball approach. The invitation letter described the intent of the study, offering participants no compensation other than the experience with the tool. Moreover, interviews were carried out in a time span of 6 weeks using a virtual platform, Zoom was the selected 
software as suitable to support this study given the rapid incorporation into home-office practices.

Sessions took place as follows: firstly, after receiving confirmation via email of interest by the participants, a follow-up email discussed the meeting details. Initially, the invitations were extended to 10 participants with an initial response of 10 out of 10 . However, the resulting number of interviews is 9 with one participant not able to assist the session. The format of the interview is described in detail this section.

Individual interviews were performed from home. After confirming consent of participation, a brief introduction was delivered to improve the social interactions, aimed at having a much more fluid session for data collection. Introductions were prepared, which helped to build a more detailed picture of the stakeholders, advocating to the multidisciplinary nature of the field: design and non-design participants were part of the study. Before engaging in the presentation session, participants were asked to accept a screen-sharing from my computer to perform the session.

The presentation consisted of 12 slides in a pdf file (see Appendix B). Each slide contains a step in the session. At the beginning the goals of the presentation are established, the overview informs the participants, and they experienced a brief introduction, a detailed description of the content, followed by an open discussion to answer and collect data. The first step to present the tool consisted in describing the theoretical background, that led to 
the recent emergence of the Design for Behaviour Change field. The introduction is then followed by a detailed description of the tool. The tool framework is now introduced and explained in the cards. Then, each dimension is presented individually, and the four corresponding approaches are described to address the elements present on both sides of the card- dimensions, principles, influence axis, and archetypes. The description of the use is also explained point by point during the session. After describing the operation of the content of the cards, a description of each dimension and their different degrees of influence is delivered.

Furthermore, the overall application of the entire deck, and an example of the resulting configuration are described to the participants. This stage is then continued with an example, aimed at solidifying the information of the tool. According to data gathered by the City of Ottawa and facilitated by the author, the example addresses a current plan outlined the aims of improving waste diversion. Three archetypes are created and included on the cards based on research carried out as part of the city plan. The example overviews a case in multiresidential buildings with three different personas. This is with the intention to engage the participants with the narrative of the existing situation, underlining the needs, attitudes, and barriers of the suggested personas. This concludes with the example of a suggested set of cards that would inform the next phase in the provided methodology for the tool.

After the presentation is complete, it was suggested that participants engage in a brief discussion to address possible unmentioned questions and enrich the data collection. Before 
finishing the session, participants are invited to complete an online survey with the link provided via a follow-up e-mail.

Summarizing, this section has presented a detailed description of the study phase in the project. It considers an overview of the planning, activities, instruments, participants, and implementation of the project illustrated in this section: all created with the intent of serving to collect the data. Each step of the study is described in detail to set the ground for the results section. 


\section{RESULTS}

This section centers on presenting the results, and the analysis methods that served in their development in a descriptive manner. The section unfolds in three parts: firstly, a subsection explains how qualitative data is analyzed, and the results are described in a pragmatic approach. This is followed by another subsection that centers on the description of the analysis of the quantitative data to describe later its results. To conclude the section, a global overview of the results and a brief description that will be later augmented in the findings section, are included in the end of the chapter.

Our timeframe for data garnering consisted of six weeks during the summer months of July and August 2020. This timeframe encompasses both activities, implementing interviews, and distributing online questionnaires. In compliance with the programmed agenda of the study, once the sessions were carried out, the sets of data were then grouped according to their research type- quantitative and qualitative. As mentioned in the methods section, prior efforts in the field support the use of qualitative research. Continuing in such a stream, a manual coding approach is adopted to categorize the data. In this manner, two coding cycles were performed over the collected data in order to reveal results. These qualitative sets of data have been categorized through a coding method, to be analyzed, compared, and discussed, in the following sections, ultimately, serving to formulate conclusions. In a similar manner, qualitative data from the online questionnaires was collected to be illustrated in this section. Before illustrating the results, we lay a brief overview of the data gathered from 
interviews and surveys. Secondly, these two sets of data merge to gain an integrated view of the qualitative data, interview sessions' transcripts, and the survey's qualitative proceedings are equally merged into a digital format for their analysis and the results are contained in Table 3.

\subsection{QUALITATIVE RESULTS}

Qualitative data proceedings split into two main themes: tool, and workshop. These two topics are described in detail in the upcoming paragraphs. The descriptions maintain an individual approach that explains the results regarding the workshop, and then the tool. Later, all the qualitative data is included below in a table that outlines a global overview of the qualitative results.

\subsubsection{INTERVIEWS}

Interviews served as the platform to generate qualitative data in the form of transcripts, observational notes, and memos. During the interviews, participants of two different fields observed a session conformed by the very same presentation materials. However, slight variations in the execution of the session must be acknowledged. In general, most of the sessions were carried out in a similar manner, concluding in a rich discussion after the presentation of the tool. Discussions developed in an organic manner, breeding a series of different themes. Resulting data is presented below with the purpose of informing the reader with the initial set of proceedings. 


\subsubsection{SURVEYS}

Data collected in the survey formed two sets of data: one qualitative and another one

quantitative. Qualitative answers have been included as part of the data analyzed that derived

in Table 3. Conversely, the resulting usability scores are shown below in this section, as they conform to the quantitative data of this study. Information shown in the table below, aims to provide a better understanding of the data, which has been clustered into codes, subcodes, categories, and themes; based on its particular features, according to the coding methods

described in Chapter 3. The resulting data pivots on two main themes: tool, and workshop (which are divided into categories, subcodes, and codes shown in Table 3).

Table 3. Qualitative Results.

\begin{tabular}{|c|c|c|c|}
\hline Theme & Category & Subcode & Code \\
\hline \multirow[t]{6}{*}{ Tool } & Documents & Manual & $\begin{array}{l}\text { Examples } \\
\text { Exploratory Boundaries } \\
\text { Instructions } \\
\text { Archetypes Guide } \\
\text { Completion Duration }\end{array}$ \\
\hline & & Expansion & $\begin{array}{l}\text { Tactics } \\
\text { Guidelines }\end{array}$ \\
\hline & Advantages & Achievements & $\begin{array}{l}\text { Configuration Flexibility } \\
\text { Promising Direction } \\
\text { Archetypes } \\
\text { Multi-level Capability } \\
\text { Timesaving }\end{array}$ \\
\hline & Deficiencies & Design & Color Scheme \\
\hline & & Framework & $\begin{array}{l}\text { Define Stakeholders } \\
\text { Increase Segments } \\
\text { Increase Archetypes }\end{array}$ \\
\hline & & Content & Avoid Jargon \\
\hline \multirow[t]{2}{*}{ Workshop } & Engagement & Participatory & $\begin{array}{l}\text { Practical } \\
\text { Demonstration }\end{array}$ \\
\hline & & Prior & Document Access \\
\hline
\end{tabular}




\subsubsection{QUALITATIVE OVERVIEW}

Data collected during the interview sessions such as transcripts, observational notes, comments, and memos, along with the qualitative data set garnered in the surveys was merged and analyzed following a coding methodology as mentioned above to develop the results of this study. Data was used to identify codes, subcodes, themes, and categories, after the analysis of the sessions' proceedings; the results can be divided into two main categories- deficiencies, and advantage. An interpretative description of these results is elaborated in the following section.

\subsection{QUANTITATIVE DATA}

In order to strengthen the validity of this project, quantitative data was also included in the selected methods that conform to our approach. Quantitative data was collected through a post-study questionnaire, distributed among participants who have previously completed the interview session. This questionnaire aimed at collecting two types of data as shown in Figure 17. Quantitative questions in the survey, followed a System Usability Scale structure that is described in detail below. Data collected from the questionnaire is analyzed using a statistical analysis to determine the usability score of the system perceived and reported by the stakeholders.

\subsection{SYSTEM USABILITY SCALE}

Measuring subjective values such as perception is a challenging endeavor. The HCI field has faced such a challenge since the 1980 's. The need of a method that would allow professionals 
of this field to measure progress in their proceedings, resulted in the creation of usability scales. Based on different factors such as historical background, serious growth, and versality; the SUS is selected to approach the opportunity areas of the DBC tool in an exploratory manner, by gathering quantifiable insights from users' perceived usability. Results from the System Usability Scale are presented in a graphical manner in Figure 18, and then described and analyzed in the next section. 

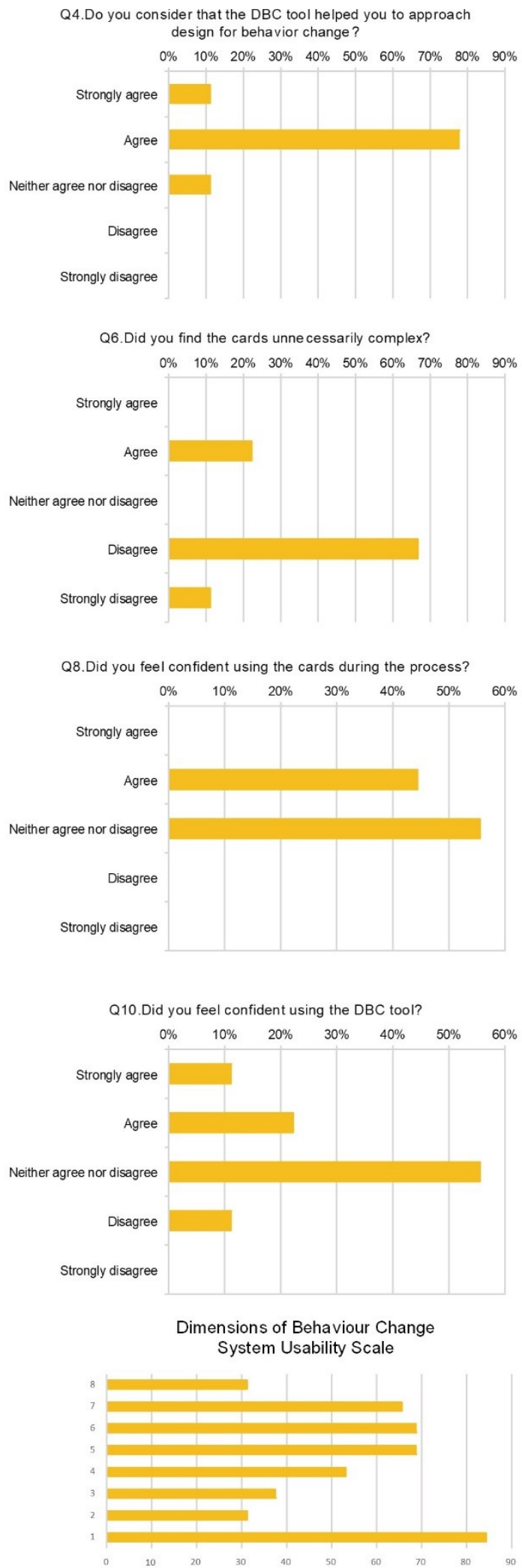

Figure 18. SUS Results.

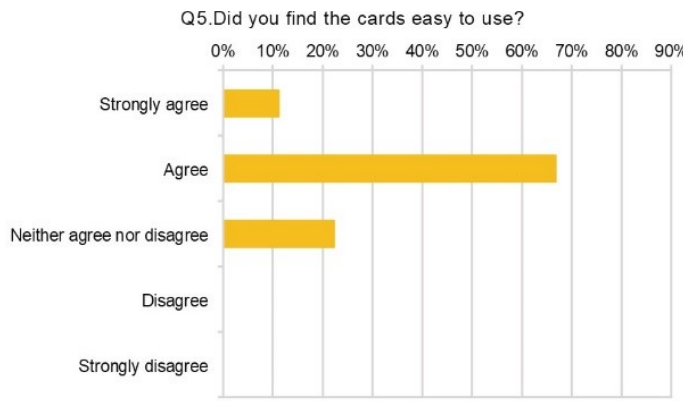

Q7.Do you consider technical support would be needed to use the system?

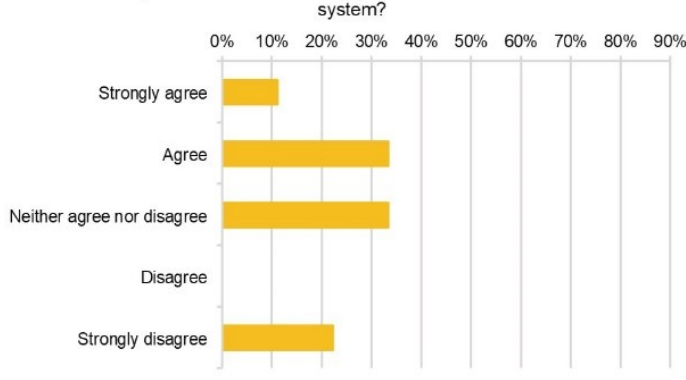

Q9.Did you think there was too much inconsistency in this tool?

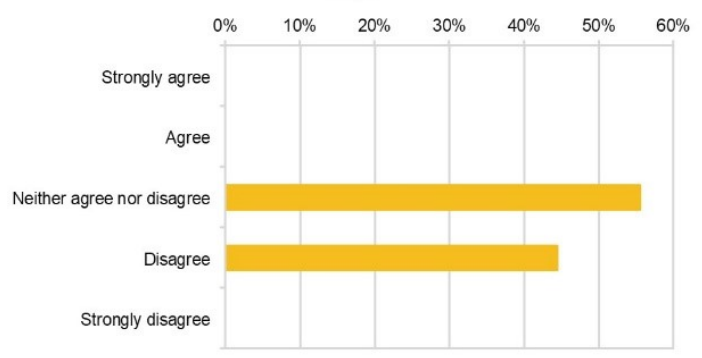

Q11. What is the overall satisfaction of the DBC tool?

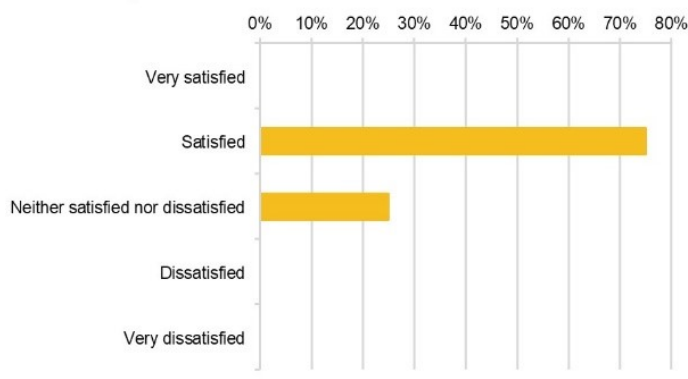

\begin{tabular}{c|c|c|c}
\hline Mean & \multicolumn{1}{c}{ Median } & Range & SD \\
\hline 55.07 & 59.43 & 53.12 & 18.68
\end{tabular}




\subsection{QUANTITATIVE RESULTS}

Based on the integral approach that defines this project, the quantitative data is processed according to the System Usability Scale (SUS). The SUS scores are analyzed based on a 0 to 100 range (Brooke, 1996). Quantitative results from the usability questionnaire show an overall score of 55.07. Industry standards are shown in Table 4. According to this tabulation, scores below 68 are deemed as 'poor' (Bangor, 2009). When contrasting our results with industry standards, it is evident there is a need of improvement in the usability of the tool. On the other hand, the scale also mentions that scores below 51 are described as 'awful'.

Table 4. SUS Score Ranking.

\begin{tabular}{ccc} 
SUS SCORE & GRADE & ADJECTIVE RANKING \\
\hline$>80.3$ & A & Excellent \\
\hline $68-80.3$ & B & Good \\
\hline 68 & C & Okay \\
\hline $51-68$ & D & Poor \\
\hline$<51$ & F & Awful
\end{tabular}

\subsection{OVERALL RESULTS}

The overall landscape of the results of this study, illustrate advantages of the method, but more importantly, opportunities that must be addressed in order to improve the usability of the tool. The diagram (see Figure 19) shows the overlapping themes in the surveys, interviews, and SUS. It reflects the need of a detailed manual that would clarify doubts, instructions, and concerns, to aid administer the tool in a clear mode. 
Perhaps a methodological approach would aid in isolating and identifying features that will eventually shape aid progressing towards better results. This topic along with other interesting findings are discussed in the following section.

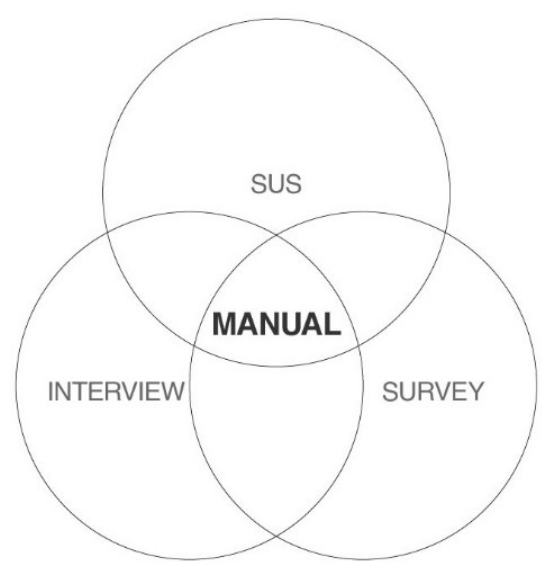

Figure 19. Triangulation of Tool Needs. 


\section{FINDINGS}

This chapter sets out to illustrate the findings of this study, which emerge from the interpretative analysis of the results. The chapter lays the findings in the following manner. It begins by moving from the general to particular needs and details that require attention. The findings are divided into four main topics: field, process, tool, and workshop. Firstly, we describe findings in this particular project, and later they are compared with similar studies in the field to identify gaps, similarities, and variations, that will later be discussed in the next section.

\subsection{FIELD}

Findings from the study have produced a rich set of insights from valued participants whose input helped in uncovering important details that are described in this section. Design for Behaviour Change is still an emerging field. Fortunately, it has drawn substantial attention in academia, and now it is exploring a potential expansion into the public and private sectors. This study aided to uncover the existing need from both sectors in proceedings from this field. It is clear that behaviour is being studied in different fields, and design has a great opportunity to contribute to endeavors that help uncover the underlying dynamics of this interesting topic. However, the field still has some tasks to complete in order to underpin the foundation and achieve concise objectives. 
Insights from this project have surfaced the following needs in the field: common terminology, defined stakeholders, standard procedures such as variables to be measured, data-collection instruments, and a distribution channel.

A common terminology would greatly aid in maintaining a homogenous language when generating discussions, sharing ideas, and communicating concisely across the field. Moreover, the need of a defined stakeholder also became evident in the findings. Although, practical incorporation of proceedings is still at an early stage, defining the stakeholder is an important step that will help shape the way that proceedings are designed, and delivered. During this project, we selected participants from public and private sectors: both profiles showed knowledge of the field. However, the expectations on the reach of the tool was consistently different. Designers, on the one hand, showed a uniform attitude regarding the intended use of the tool in the design process, which is to aid in the generation of ideas aimed to overcome behavioural challenges. Whereas non-designers expected the tool to provide an expanded scope, such as a set of guidelines or tactics to apply in practice. This difference lies in the level of design education, and can be linked to what is known as being design literate or design literacy. The difference is described by Pacione (2010, p. 9) "as opposed to being a design professional, [it] is basic skills in inquiry, evaluation, ideation, sketching, and prototyping”. Therefore, the need of defining the stakeholders of proceedings in the field is an important finding from this study. If the tool is intended for design literate 
stakeholders instead of designers, a complementary section of tactics or guidelines is suggested.

\subsection{PROCESS}

This subsection addresses the findings regarding the tools and their place in the design process. Acknowledging the early stage of the field helps to understand the wide range of opportunities to improve. In the developing of solutions in the field, proceedings have aided design at different levels, some efforts focus on theoretical frameworks, others on practical examples by generating case studies, and some others develop tools that are designed to be integrated into design processes, like the one this project sets out to investigate. Different frameworks have been developed to outline the integration of proceedings such as tools into practical process(es). Variations in the intended purpose of these tools affect their position in the process. Before we continue with the findings, we must highlight that developing a tool entails a large set of steps that are not entirely defined. Expanding on this notion may be beneficial to the design field. Therefore, any developed tool must take into consideration to its location in the design framework, which will inform its features, scope, and capabilities, that will ultimately enable the tool to correctly perform in praxis. Additionally, the process must be described in great detail in the manual, encompassing all the steps that are needed for its best usage. 


\section{$6.3 \mathrm{TOOL}$}

The focal point of this project is the Dimensions of Behaviour Change Tool. Its previous iteration developed by Boks is redesigned for this study. The need of an iteration is supported in the argument after the analysis of the tool design. Our approach led to a set of 27 individual cards containing 3 different settings of each of the 9 dimensions. Some dimensions were rephrased, and the developed segments of their agency axis were rephrased as well. The tool served our purpose as a data-collection instrument, that helped generating discussions and gaining insights from the participants. Feedback highlights a set of important findings about the tool. Some positive features such as the integration of archetypes, and the use of specific segments of the axis were reported as positive. Archetypes allowed stakeholders to make sound connections between the users and the approaches that would aid them exploring possible outcomes. Similarly, dividing the spectrums in defined segments and providing them with a name, helped in locating the approach in a more precise manner. On the other hand, opportunities like the need of a manual that encapsulates all the details of the tool, such as its limits, its exploratory purpose, timeframe of application, number of participants, instructions for the cards, creation of archetypes, examples either for each principle or in a case study where they are identified, and the inclusion of more segments to allocate a wider range of archetypes or personas, emerged from the study. These findings are also supported by the quantitative results, which denote a usability score with a large room for improvement. 


\subsection{WORKSHOP}

Continuing our prior stream, findings regarding the selected format to present the tool, are described in two primary themes: exploits and shortfalls. We begin by describing the positive features of the sessions. The results point out advantages of presenting tools in an interview format, such as preserving the amount of information limited to essentials. This reduced the interaction time with participants and delivered the information in a precise and clear manner. However, the timeframe resulted in an over-reduction of the time needed to absorb all the information and details of the tool. Findings suggest, that enabling stakeholders with prior access to the tool to become familiarized and study it at their own pace, would be greatly beneficial. Similarly, the scope of the presentation was limited, and the example provided in the session, only allowed participants to observe a finalized example. Conversely, a wide majority would have appreciated a more practical activity that would have allowed them to try the tool and learn more about its functionality. As mentioned in the methods chapter, the presentation suffered changes that affected the reach of the sessions. COVID-19 changed the manner in which this project was developed. The rapid adjustments in the methodology reduced the interactions to accommodate the new requirements. Although limited, this format enabled the project to uncover interesting findings at different levels.

Findings have shown advantages and shortfalls of different levels approached in throughout this project; findings are summarized in Table 5 , thereby describing necessary changes to improve the identified deficiencies. 
Table 5. Findings Summary.

\begin{tabular}{|c|c|c|c|}
\hline Theme & Strength & Shortfall & Must \\
\hline \multirow[t]{4}{*}{ Field } & Interest & & $\begin{array}{l}\text { The actual direction that pursues } \\
\text { results at theoretical and practical } \\
\text { levels has had an important influence } \\
\text { in existing outcomes. }\end{array}$ \\
\hline & & Methodology & $\begin{array}{l}\text { Develop a standard procedure to } \\
\text { produce knowledge in a uniformed } \\
\text { manner. Defining measurable } \\
\text { variables, data collection instruments, } \\
\text { as well as short, and long-term } \\
\text { objectives. }\end{array}$ \\
\hline & & Stakeholders & $\begin{array}{l}\text { Outline the targeted user(s) of } \\
\text { proceedings from the Design for } \\
\text { Behaviour Change field. This will aid } \\
\text { in having a better picture of their } \\
\text { needs and skills, which may result in } \\
\text { better outcomes. }\end{array}$ \\
\hline & & Terminology & $\begin{array}{l}\text { A common terminology would enable } \\
\text { the field with consistent notions that } \\
\text { would support richer discussions. }\end{array}$ \\
\hline Process & Framework & & $\begin{array}{l}\text { The framework proposed in this study } \\
\text { for the inclusion of the DBC tool, } \\
\text { builds on the relation between the } \\
\text { main goal of the tool and a linear } \\
\text { design model, which received a } \\
\text { positive input from the participants. }\end{array}$ \\
\hline \multirow[t]{4}{*}{ Tool } & & Manual & $\begin{array}{l}\text { Develop a clear and concise manual } \\
\text { that describes the entire set of } \\
\text { features, its limits, mode of } \\
\text { administration, theoretical foundation, } \\
\text { application timeframe, suggested } \\
\text { framework, detailed steps that include } \\
\text { before and after procedures, support } \\
\text { the creation of archetypes, include } \\
\text { examples of each principle, and state } \\
\text { the exploratory perspective of the } \\
\text { tool. }\end{array}$ \\
\hline & Flexibility & & $\begin{array}{l}\text { Maintain the flexibility and make it } \\
\text { clear in the instructions. }\end{array}$ \\
\hline & Archetypes & & $\begin{array}{l}\text { Keep the archetypes and explain their } \\
\text { use in the tool's manual. }\end{array}$ \\
\hline & & Segments & $\begin{array}{l}\text { Segmentation of the spectrums must } \\
\text { be enlarged to allow for more }\end{array}$ \\
\hline
\end{tabular}


variations and include a wider range of archetypes.

Multi-level Capability

The tool's capability to aid in the design of both, systems, and artifacts must be described in the manual.

Workshop Fundamentals

Reducing the content to its more essential elements must be preserved in the presentation of the tool.

Breadth

The workshop would greatly benefit from expanding the duration and integrating a comprehensive experience, considering prior access to the tool and a practical exercise.

To summarize, findings have revealed a substantial and interesting set of details regarding not only the tool, but the field as well. They have also helped in supporting further studies after confirming the interest from private and public sectors, in this field and its practical proceedings. The following section offers a rich discussion regarding a comparison of findings emerged from this study and findings from similar existing studies in the field. 


\section{DISCUSSION}

This section sets out to present a discussion enriched by the findings identified in this study, and others pinpointed in similar studies. The purpose of this project has been to shed light on the capabilities and affordances the Dimensions of Behaviour Change tool may have to offer in praxis. This study investigated its possible application by reaching out to professionals, whose experience rendered them able to provide advice and point out the advantages and opportunity areas of the tool. These insights were collected using a set of three instruments: interviews, surveys, and a new DBC tool iteration. Findings have been described in the previous chapter and now an overall discussion regarding the journey of answering our research question is presented. Our project leans directly on prior work of Daae and Boks, whose effort have enlarged the collection of additions in the Design for Behaviour Change field. Their work provided this project with the ground to develop the study. This consequently produced findings that are categorized in four segments: field, framework, tool, and workshop (which are described in this section in the following manner). Each one of the categories is contrasted with similar existing examples in the field and discussed individually with the intention of identifying similarities and discrepancies, in a methodical fashion. The author concludes the section with a summary of the most significant outputs of the discussion, serving as a prelude to the project conclusions. 


\subsection{FIELD}

This project resulted in a rich collection of findings that have been grouped according to their level of application in the theoretical-practical spectrum. This section focuses on discussing the contrast of findings in this study with similar studies in the field of Design for Behaviour Change. It will address point by point, a comparison of the findings that emerged regarding the field, and pair it with existing results. Following a suggested approach in the work of Niedderer et al. (2016), our participants criteria successfully recruited professionals in private and public sectors. Their input resulted in a significant amount of details that are discussed in this section. Among other important findings, participants reported a high interest in proceedings that would aid them to take informed directions in behaviour change challenges. These results highlight the existing interest in these sectors, especially in proceedings such as guidelines and toolkits. Equally important, the emergence of evidencebased examples was also a recurrent theme among non-design participants. As they suggest there is a need of directing future efforts towards producing evidence and trackable results of the produced advances in the field. Conversely, one significant finding is the requirement to define stakeholders' needs to meet them accordingly. In their prior study, Niedderer et al. (2014) list the categories for different stakeholders: professional practitioners, academia, and policymakers. All three categories englobe possible stakeholders of proceedings from the field. However, variations in their skillsets call for different capabilities and features from particular proceedings. This became evident in this project, when expectations from the tool 
capabilities varied from the collected responses from the participants. As mentioned in the findings section, designers agreed on the intended application of the tool, which is to empower stakeholders with knowledge in the form of principles to address behaviour challenges. In other words, the role of the tool was clear and no comments were made regarding the place of the tool within the framework. Whereas non-designers, frequently suggested the need of a complement for the tool, that would aid them to implement the resulting configuration of the DBC tool, in the form of guidelines, best practices, or tactics. This discrepancy between the stakeholders' groups, would definitely impact the performance, outcomes, and experience of the stakeholders. Lastly, there is a need of a common language that enables effective communication among researchers in academia, and stakeholders in private and public sectors.

\subsection{FRAMEWORK}

Although the important attention gained in recent decades, this field is still progressing towards a more mature phase. This characteristic renders visible in the literature review, as the number of existing frameworks is still limited. Continuing on the reductive principles delineated in the design of the tool, and perhaps, the entire study, have equally permeated the framework proposed in this project (see Figure 16) maintains a simplified approach, and has been reported, according to our findings, as clear and easy-to-grasp. When compared to the approach selected by the DBC tool developers, that builds on Zachrisson et al. (2011) model, it has richer amounts of information that suggest a strong sustainable purpose. It may 
be valid to say that the DBC tool remains flexible to different frameworks. However, it is crucial to highlight the need of prior detailed research to outline precise targets in order to have a clear set of barriers and goals to aim to when using the DBC tool. Our argument points out the elastic purpose of the tool, serving as connector between research and ideageneration stages within a design framework. Contrastingly, when compared with the DwI, Lockton (2013) establishes an undefined framework for his method, supported on an empirical approach, and perhaps done with exploratory purposes. This lack of structure offers a different perspective to learn more about the practical applications of the method. However, it also renders it challenging to track, measure, and analyze the insights that may improve the tool.

\section{$7.3 \mathrm{TOOL}$}

Returning to our focal point, the tool remained as the central focus during the project, operating as instrument, outcome, and discussion topic. This section lays the discussion around the contrasting findings regarding the tool. As defined in the study section, this project developed an iteration of the DBC tool described by Daae and Boks (2017). Its design draws on HCI principles following the notion that the tool conforms an interface and thus these principles would improve the resulting design, which would be later measured using a System Usability Scale. Changes in the resulting tool are documented throughout the thesis. The incorporation of the archetypes in the layout of the tool, resulted in a great axis to 
generate discussion and make a quick connection between the user (or persona), and the principle.

\subsection{WORKSHOP}

The administration of the sessions was initially planned following laboratory configuration, with participants from both fields (design, and recycling), collaborating in a group setting, and with a duration of 3 hours in a controlled physical space. As we mentioned above, due to unforeseen happenings its scope was affected, reducing the duration to 45 minutes, moving to an online platform, and changing into a 1 on 1 interview session. These challenges impacted the findings and made evident the need of extending the sessions' lengths.

Conversely, these shortfalls were satisfied in studies by Lockton (2013), who ran, and refined a series of workshops with graduate students, and professionals, garnering data and shaping the DwI method progressively. In a similar manner, Daae ran a series of workshops with the intention of collecting data to measure the efficacy of the DBC tool. Moreover, it is important to mention the objectives of each workshop differs from one another.

To conclude, this section has prepared the grounds for the final chapter. The conclusions of this project are delineated in the next section. Significant findings in this study have found similarities and strengthen previous studies with valued insights. Additionally, the identified gaps have also shed light on unknown areas that need attention in future endeavors. 


\section{CONCLUSIONS}

This chapter culminates the efforts of this project, by answering our initial question. The answer is formed in a narrative manner to prepare the ground for the set of conclusions.

From an exploratory perspective, this project has resulted in two main veins: insights and the unknown futures. Insights have clearly revealed valued information that supports the existing interest in proceedings in the field by both sectors: private and public. Results produced in this project, which originated as the framework to answer the research question, have shaped not only an answer, but, perhaps more importantly, they also produced a new set of questions. Such dichotomy is elaborated further in this section in the form of conclusions, regarding the tool, the frameworks, the field, and to some degree, design as well. Starting with the grounds that served to produce this project, the first endeavors that aimed to form connections between social sciences and design models, have produced a considerable number of proceedings over the last two decades. It has been established, that

efforts draw on two perspectives: behavioural psychology and sociology. Both investigate the same phenomena at different levels: individual and contextual. As we delineated in the literature review, the DBC tool draws on behavioural psychology grounds. However, this project, found that the tool is potentially useful on both levels. This flexibility comes with advantages and shortfalls as well, and it may be challenged when compared with a more specific method. Therefore, it is important to define the intention and limits of the tool, informing clear and concise expectations of the stakeholder. Similarly, the distribution 
modality for proceedings requires attention. Based on the interviews that shaped this study, it is clear that the tool is still at an early stage, and its proper application in practice is still to be defined.

To answer our research question, the results recognize the potential in the tool to aid designers in behavioural challenges. After revising the results, and reflecting on the experienced interactions, and weighing the evidence, the answer to the research question is: That the tool is fitted to serve an exploratory mode in practice, not only for designers, but also professionals facing behavioural change challenges, as it fosters rich, theory-based discussions, that serve as a platform for a more concrete, revised direction.

To conclude in a few words, it can be said that following improvements in the field must define a user, delineate a methodology, and regarding the tool, it must create a precise manual, and expand the collaborative activities to develop future iterations. 


\section{REFERENCES}

Aldersey-Williams, H., Bound, J., and Coleman, R. (1999). The Methods Lab | User Research for Design. Helen Hamlyn Research Centre, Royal College of Art, London, UK.

Akrich, M. (1992). The De-Scription of Technical Objects. In Shaping Technology/Building Society: Studies in Sociotechnical Change, ed. W. E. Bijker and J. Laws. Cambridge, MA. MIT Press.

Baber, C. (2005). Evaluation in human- computer interaction. In Evaluation of human work. Boca Raton, FL.

Bangor, A., Kortum, P., and Miller, J. (2009). Determining what individual SUS scores mean: Adding an adjective rating scale. Journal of usability studies, 4(3), 114-123.

Boks, C., Daae, J. (2013). Towards an increased user focus in life cyde engineering Re-engineering Manufacturing for Sustainability. Proceedings of the 20th CIRP International Conference on Life Cycle Engineering, Singapore 17-19 April 2013.

Boks, C., Lilley, D. and Pettersen, I.N. (2015). The future of Design for Sustainable Behaviour, revisited. Proceedings of the EcoDesign2015: 9th International Symposium on Environmentally Conscious Design and Inverse Manufacturing, Tokyo, Japan, December 2-4, 2015.

Buchanan, R. (1990). Myth and maturity: toward a new order in the decade of design. Design Issues 6(2), 7080.

Latour, B. (1992). Where A re the Missing Masses? The Sociology of a Few Mundane A rtifacts, in Shaping Technology/Building Society: Studies in Sociotechnical Change, ed. W. E. Bijker and J. Laws (Cambridge, MA: MIT Press).

Carroll, J. (1997). Human-computer interaction: psychology as a science of design. Annual review of psychology, 48, 61-83.

Chatterton, T. and Wilson, C. (2014) The 'Four Dimensions of Behaviour' framework: a tool for characterising behaviours to help design better interventions. Transportation Planning and Technology, 37(1), 38-61, doi: $10.1080 / 03081060.2013 .850257$

Cialdini, R. B. (1993). Influence: Science and practice (3rd ed.). HarperCollins College Publishers.

Coskun, A. and Erbug, C. (2014a). Designing for Behaviour Change: Smart Phone A pplications as Persuaders of ProE nvironmental Behaviours. METU Journal of the Faculty of Architecture. 31. 215-233.

10.4305/METU.JFA.2014.1.11.

Coskun, A. and Erbug, C. (2014b). User diversity in design for behavior dhange. Proceedings of DRS, 2014. 546-559.

Crotty, M. (1998). The Foundations of Social Researdh: Meaning and Perspective in The Research Process. Sage publications Ltd. 
Daae, J., Boks, C. (2014) Dimensions of behaviour dhange. Journal of Design Research, 12(3), 145 - 172.

Daae, J., Boks, C. (2017). Tweaking interaction through understanding the user. In Design for Behaviour Change: Theories and Practices of Designing for Change on 23 August 2017, https://doi.org/10.4324/9781315576602.

Denzin, N. K., and Lincoln, Y. S. (2005). Introduction: The Disaipline and Practice of Qualitative Research. In N. K. Denzin and Y. S. Lincoln (Eds.), The Sage Handbook of Qualitative Research (pp. 1-32). California: Sage Publications.

Lilley, D. (2009). Design for sustainable behaviour: strategies and perceptions. Design Studies, 30, 704-720.

Lilley, D., Bhamra, T. A. and Lofthouse, V. A. (2006). Towards Sustainable Use: A n Exploration of Designing for Behavioural Change. DeSForm 2006: European Workshop on Design and Semantics of Form and Movement. Eindhoven, The Netherlands.

Fogg, B. J. (2003). Persuasive Technology. Using Computers to Change What We Think and Do. Interactive Technologies, Morgan Kaufmann.

Frayling, C. (1993). Research in A rt and Design. Royal College of art Research Papers, 1(1), 1-5.

Friedman, K., (1997) Design science and design education. In McGrory, Peter (ed) The challenge of complexity, University of Art and Design Helsinki UIAH, Helsinki, 54-72.

Friedman, K., (2000). Creating design knowledge from research into practice. IDATER 2000 Conference, Loughborough: Loughborough University

Friedman, K. (2003). Theory construction in design researd: criteria: approaches, and methods. Design Studies, 24(6), 507-522.

Golafshani, N. (2003). Understanding Reliability and V alidity in Qualitative Research. The Qualitative Report, 8(4), 597-607.

Gram-Hansen, S. B. (2010) Persuasion, E thics and Context A wareness: Towards a Platform for Persuasive Design founded in the Notion of Kairos. In: Persuasive Technology: Fifth International Conference, Persuasive 2010, Copenhagen, Denmark, June 7-9, 2010, poster proceedings, University of Oulu Department of Information Processing Science

Graziano, A., and Raulin, M. (2004). Research Methods; A process of Inquiry. 5th edition. Boston, USA: Pearson educational group inc.

Nelson, H. and Stolterman, E. (2012). The Design Way: Intentional Change in an Unpredictable World. Cambridge, MIT Press.

Hignett, S. (2005). Qualitative methodology. In Evaluation of Human Work, 3rd Edition. doi 10.1201/9781420055948.ch5.

Holtzblatt, K. and Beyer, H. (2017). Contextual Design. 2nd Edition: Design for Life. 
Gibson, J. (1977). The Theory of A ffordances. In Shaw, R and Bransford, J. Perceiving, Acting, and Knowing: Toward an Ecological Psychology 67-82. Hillsdale, NJ. Lawrence Erlbaum

Kimbell, L. (2011) Designing for service as one way of designing services. International Journal of Design, 5(2), 41-52.

Klöckner, C. A., and Blöbaum, A. (2010). A comprehensive action determination model: Toward a broader understanding of ecological behaviour using the ex ample of travel mode choice. Journal of Environmental Psychology, 30(4), 574-586, ISSN 0272-4944, https://doi.org/10.1016/j.jenvp.2010.03.001.

Lewis, J. (2018) The System Usability Scale: Past, Present, and Future. International Journal of HumanComputer Interaction, 34(7), 577-590, DOI: 10.1080/10447318.2018.1455307

Lockton, D. (2005). A rchitectures of Control in Consumer Product Design. EconWPA, Others. $10.2139 /$ ssrn. 908493.

Lockton, D., Harrison, D. and Stanton, N. (2009). The Design with Intent Method: A design tool for influenaing user behaviour. Applied ergonomics. 41. 382-92. 10.1016/j.apergo.2009.09.001.

Lockton, D., Harrison, D., Stanton, N.A. (2012). Models of the user: designers' perspectives on influenang sustainable behaviour. Journal of Design Research, 10(1/2), 7-27, doi:10.1504/JDR.2012.046137

Lockton, D. (2013). Design with Intent. Doctoral Thesis, Brunel University.

May, T. (2001) Social Researdr: Issues, methods and process, Open University Press, Buckingham.

McQueen, R. and Knussen, C. (2002) Research Methods for Social Science - A n Introduction, Prentice Hall, Harlow.

Nielsen, J. (1994). Heuristic evaluation. In Nielsen, J., and Mack, R.L. (Eds.), Usability Inspection Methods, John Wiley and Sons, New York, NY

Nielsen, J., and Molich, R. (1990). Heuristic evaluation of user interfaces, Proc. ACM CHI'90 Conf. (Seattle, WA, 1-5 April), 249-256.

Niedderer, K., Mackrill, J., Clune, S., Lockton, D., Ludden, G., Morris, A., Cain, R., Gardiner, E., Gutteridge, R., Evans, M., and Hekkert, P. (2014). Creating Sustainable Innovation through Design for Behaviour Change: Full Report. 10.13140/2.1.4817.4409.

Niedderer, K., Ludden, G., Clune, S. J., Lockton, D., Mackrill, J., Morris, A., Cain, R., Gardiner, E., Evans, M., Gutteridge, R., and Hekkert, P. P. (2016). Design for behaviour dhange as a driver for sustainable innovation: Challenges and opportunities for implementation in the private and public sectors. International Journal of Design, 10(2), 67-85.

Norman, D. (1988). The Design of Everyday Things. New York, Basic Books.

Norman, D. (2007). The Design of Future Things. New York, Basic Books. 
Ölander, F., Thørgersen's, J. Understanding of consumer behaviour as a prerequisite for environmental protection. J Consum Policy 18, 345-385 (1995).

https://doi.org/10.1007/BF01024160

Pacione, Chris. (2010). Evolution of the mind: A case for design literacy. Interactions. 17. 6-11. 10.1145/1699775.1699777.

Pantzar, M., and Shove, E. (2010). Taylor and Amp; Francis Online: Understanding innovation in practice: a discussion of the production and re-production of Nordic Walking - Technology Analysis; Strategic Management, 22(4), 447-461.

Papanek, Victor J. Design for the Real World: Human Ecology and Social Change. 2nd rev. ed. Chicago: Academy Chicago Publishers., 1984. Print.

Pettersen, I.N. (2013). Changing Practices: The Role of Design in Supporting the Sustainability of Everyday Life.

Pontis, S. (2010). 'Types and approaches of (design) research'. Mapping Complex Information blog, 5 November 2010. Available at http://sheilapontis.wordpress.com/2010/11/05/types-andapproaches-of-design-research/

Preece, J., Rogers, Y., and Sharp, H. (2002). Interaction design: beyond human-computer interaction. New York, NY, USA: John Wiley and Sons, Inc.

Raymond M. Bergner, What is behavior? And so what?, New Ideas in Psychology, Volume 29, Issue 2, 2011, Pages 147-155, ISSN 0732-118X, https://doi.org/10.1016/j.newideapsych.2010.08.001.

Robson, C. 2002. Real World Research, Blackwell Publishing, UK.

Shackel, B. (1984). The concept of usability. In: J. Bennett, D. Case, J. Sandelin and M. Smith (eds) Visual Display Terminals: Usability Issues and Health Concerns (Englewood Cliffs, NJ: PrenticeHall), pp. 45-88.

Simon, H. (1996). The sciences of the artificial. Cambridge, MA, USA: MIT press.

Stern, P., (2000). Psychology and the science of human-environment interactions. American Psychologist.

Strengers, Y. (2010). Conceptualising everyday practices: Composition, reproduction and change. RMIT Working Paper No. 6. Melbourne: RMIT.

Tang, Tang and Bhamra, Tracy. (2008). Changing energy consumption behaviour through sustainable product design. INTERNATIONAL DESIGN CONFERENCE - DESIGN 2008, Dubrovnik - Croatia, May 19 - 22, 2008. Dubrovnik, Croatia, $19^{\text {th }}-22^{\text {nd }}$ May, pp.1359-1366. 
Trudel, R., and Argo, J. J. (2013). The Effect of Product Size and Form Distortion on Consumer Recycling Behavior. Journal of Consumer Research, 40(4), 632-643.

https://doi.org/10.1086/671475

Verbeek, P. P. C. C., and Slob, A. (2006). User behavior and technology development: Shaping sustainable relations between consumers and technologies. (Eco-efficiency in industry and science; Vol. 20). Dordrecht: Springer. https://doi.org/10.1007/978-1-4020-5196-8

Watson, J. (1994). Psychology as the Behaviorist V iews It. Psychological Review, 101(2), 248-253.

Wautelet, T. (2018). The concept of circular economy - its origins and its evolution, (January). https://doi.org/10.13140/RG.2.2.17021.87523

Wever, R., Van Kuijk, J. and Boks, C. (2008). User-centred design for sustainable behaviour. International Journal of Sustainable Engineering, 1, 9-20.

Wilson, G. (2013). Design for sustainable behaviour: feedback interventions to reduce domestic energy consumption.

Wu, D. W. L., Lenkic, P. J., DiGiacomo, A., Cech, P., Zhao, J., and Kingstone, A. (2018). How does the design of waste disposal signage influence waste disposal behavior? Journal of Environmental Psychology, 58(June), 77-85. https://doi.org/10.1016/j.jenvp.2018.07.009

Zachrisson, J., Storro, G., Boks, C., (2011). Using a guide to select design strategies for behaviour change; Theory vs. Practice. Proceedings of EcoDesign 2011, Design for Innovative Value Towards a Sustainable Society, Kyoto, Japan, Nov. 30 - Des. 22011 362-367. 


\section{APPENDIX A - Interview Slides}

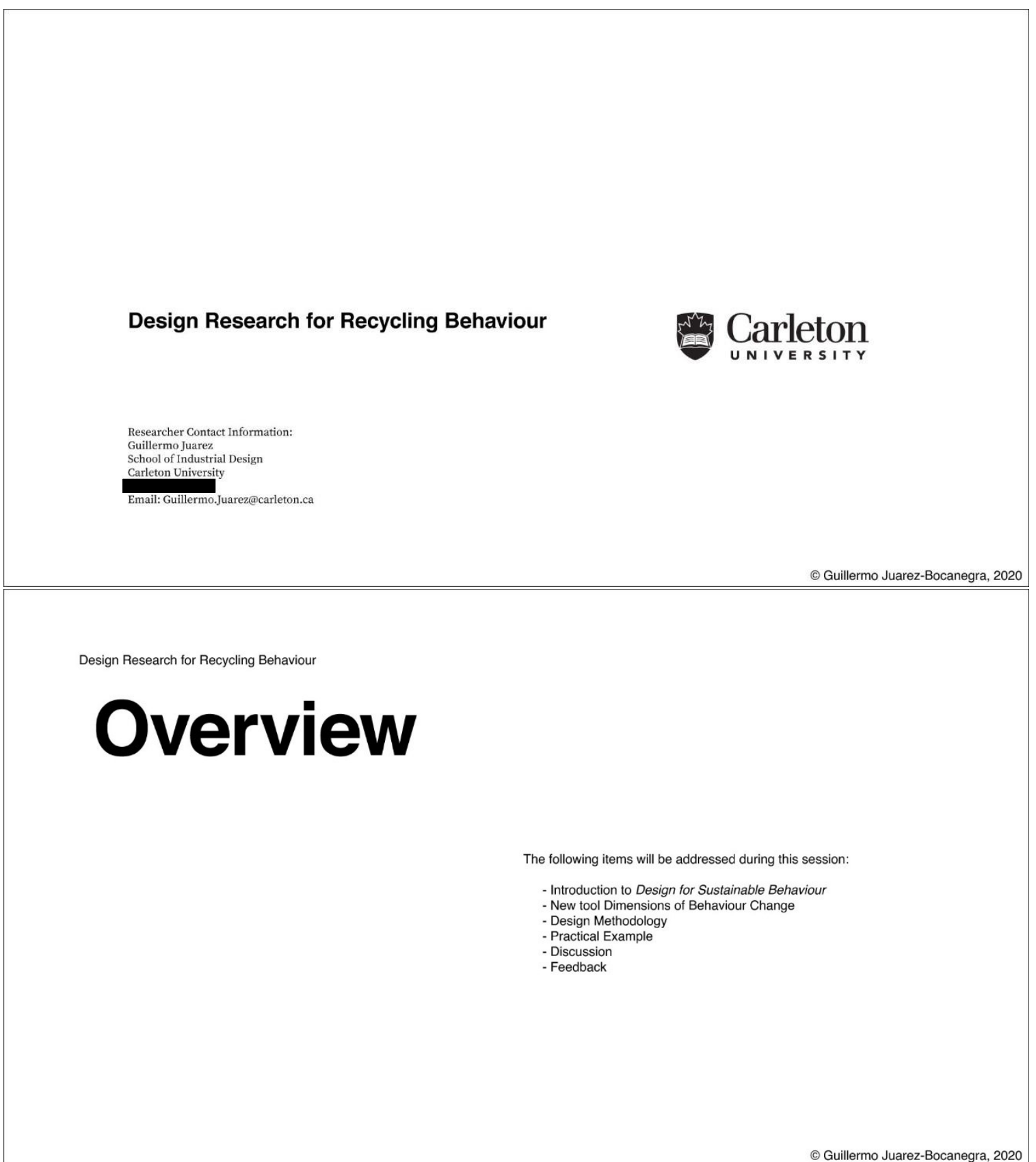


Design Research for Recycling Behaviour

\section{Background}

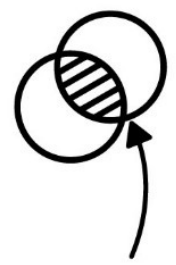

Design/Behaviour
Behaviour is a complex topic that has been a subject of study over decades by multiple disciplines, such as; sociology, pscyhology, anthropology, and political science. Design incursion into behaviora science is still at an exploratorial stage with most of the existing models and strategies in continuos refining.

Our study focuses on psychology research and the integration of behavioural models into design tools. Building on previous studies that aim to develop design tools to aid designers in the field of Design for Sustainable Behavio

() Guillermo Juarez-Bocanegra, 2020

\section{ToolKit}

The Dimensions of Behaviour Change Tool consists of 9 dimensions with bidirectional levels of intensity. The content is comprised in 27 cards, aimed to aid professionals in the behavior field. The tool was developed by Boks and Daae in 2014. This iteration has been modified for a digital environment.

Each card contains valued information that will support

decision-making at the creative process. Helping stakeholders' in

keeping a clear perspective of the particular challenges according to

different personas. 
Design Research for Recycling Behaviour

\section{Content}

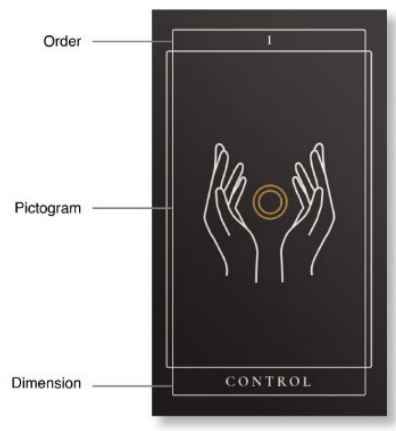

Front

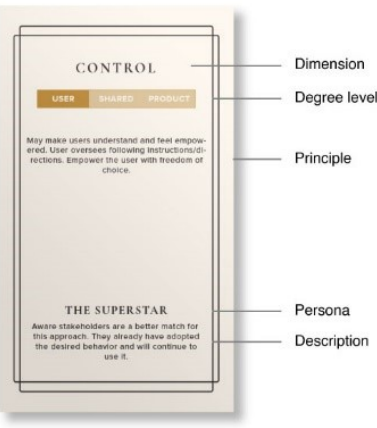

Back
- Dimension: Each dimension is depicted at the top of the card to ease of identification.

- Degree: The degree of the dimension varies according to the bidirectional outputs.

- Principle: Design principles based on the degree level indicated above will describe possible approaches.

- Persona: Stakeholder's profiles are described in this section, allowing the user to identify the profile that would fit better the selected card.

(c) Guillermo Juarez-Bocanegra, 2020

Design Research for Recycling Behaviour

\section{Application}
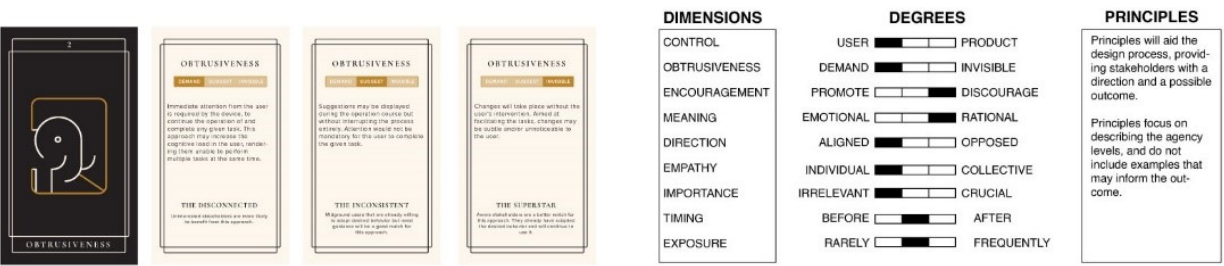

The resulting set of cards will set a configuration of degrees for all the dimensions, which will advise to the stakeholders in the creative process. Additionally, the configuration will oversee the decisions with a collection of principles that are aligned with the desired outcome. 


\section{Challenge}

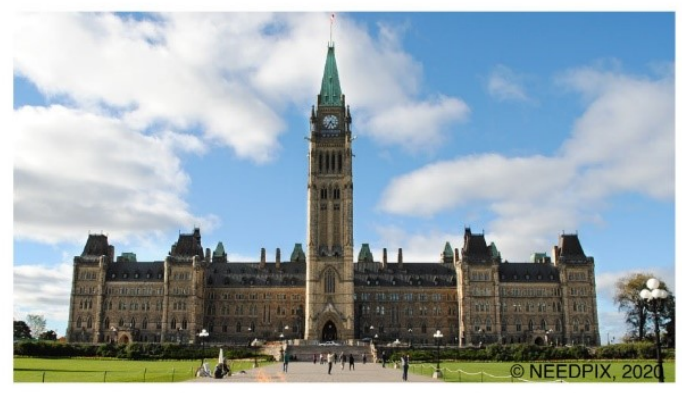

\section{MultiRes}

Ottawa is aiming to introduce a Circular Economy framework. One concrete objective is to increase waste divertion percentage in buildings that are part of the exisiting Green Bin program. Overcome the unpleasant experience reported in the research.

Barriers:

- Buildings not adopting the Green Bin program

- Lack of infrastructure in existing buildings.

Unpleasant experience due to odor.

Reduced space in habitational areas.

- Low ownership from stakeholders, mainly renters.

Young audiences uninterested.

\section{Personas}

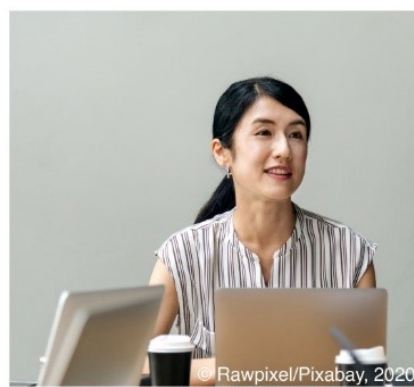

Karine

Canadian borned and raised. Lives in the suburbs. Concerned about the environment, do her best to recycle. Finds inconvinient the of a stretch.

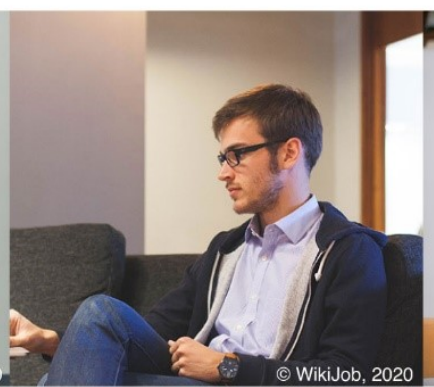

Sergio

International living and working in downtown Ottawa for 5 years. He's somewhat familiar with recycling. Not much concerned about waste. His building offers no Green Bin.

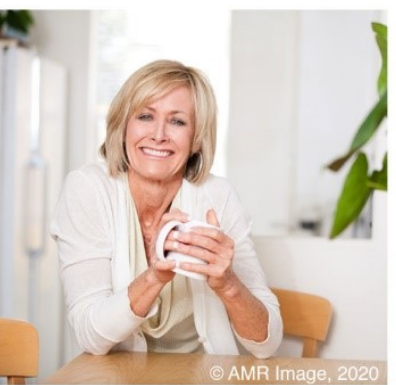

Sue

Ottawa borned and raised. Retired professional and active community member. Concerned about the rapid-changing environment, pushes for zero-waste programs. 
Design Research for Recycling Behaviour

\section{Methodologies}

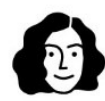

Personas

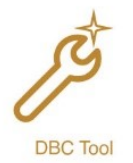

DBC Tool

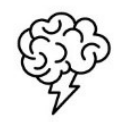

Brainstorming

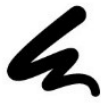

Sketching

(c) Guillermo Juarez-Bocanegra, 2020

Design Research for Recycling Behaviour

Outcome

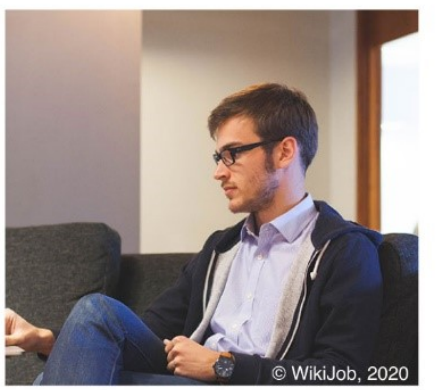

Sergio

International living and working in downtown

Ottawa for 5 years. He's somewhat familiar

zero waste, rathers not to separate organic

waste. His building offers no Green Bin.
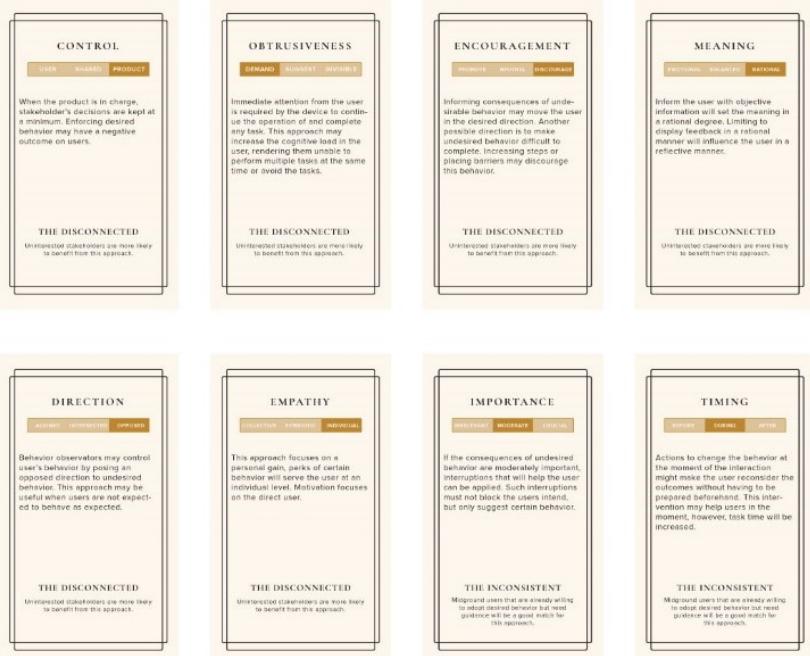

c) Guillermo Juarez-Bocanegra, 2020 


\section{Questions}

(c) Guillermo Juarez-Bocanegra, 2020

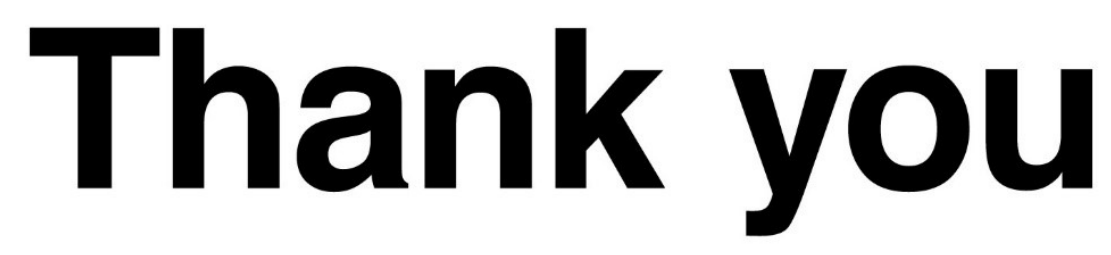




\section{APPENDIX B - Questionnaire}

\section{Carleton \\ U N I V E R S T Y}

QUESTIONNAIRE

Please read this form carefully and fill it accordingly.

1. Please mark the years and field of experience.
$1-3$ years
$3-5$ years
$5+$ years

2. Are you familiar with the field Design for Behavior Change?

Yes

No

3. If yes, please list the strategies/models/tools you are aware of:

4. Do you consider that the DBC tool helped you to approach design for behavior change? Strongly Agree

\begin{tabular}{|l|l|l|l|l|}
\hline & & & & \\
\hline & 2 & 3 & 4
\end{tabular}
Strongly Disagree

5. Did you find the cards easy to use? Strongly Agree

\begin{tabular}{|l|l|l|l|l|}
\hline & & & & \\
\hline 1 & 2 & 4 & 4
\end{tabular}
Strongly Disagree

6. Did you find the cards unnecessarily complex? Strongly Agree

\begin{tabular}{l|l}
\hline & \\
\hline & 2
\end{tabular}

\begin{tabular}{|l|l|l|l|}
\hline & & \\
\hline
\end{tabular}
Strongly Disagree

7. Do you consider technical support would be needed to use the system? Strongly Agree

\begin{tabular}{|l|l|l|l|l|}
\hline & & & & \\
\hline & 3 & 3 & 4
\end{tabular}
Strongly Disagree

8. Did you feel confident using the cards during the process? Strongly Agree

\begin{tabular}{|l|l|l|l|l|}
\hline & & & & \\
\hline 1 & 2 & 3
\end{tabular}
Strongly Disagree

9. Did you think there was too much inconsistency in this tool? Strongly Agree

\begin{tabular}{|l|l|l|l|l|}
\hline & & & & \\
\hline & 2 & 4 & 4
\end{tabular}
Strongly Disagree

10. Did you feel confident using the DBC tool? Strongly Agree

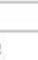

\begin{tabular}{|l|l|l|}
\hline & & \\
\hline
\end{tabular}
Strongly Disagree

11. What is the overall satisfaction of the DBC tool? Very Satisfied

\begin{tabular}{|l|l|l|l|l|}
\hline & & & & \\
\hline 1 & 2 & 4 & 4
\end{tabular}
Very Unsatisfied

12. Please share any feedback to help improve the design of the tool.

13. Please share any comments that may help improve the presentation. 


\section{APPENDIX C - Dimensions of Behaviour Change Cards}
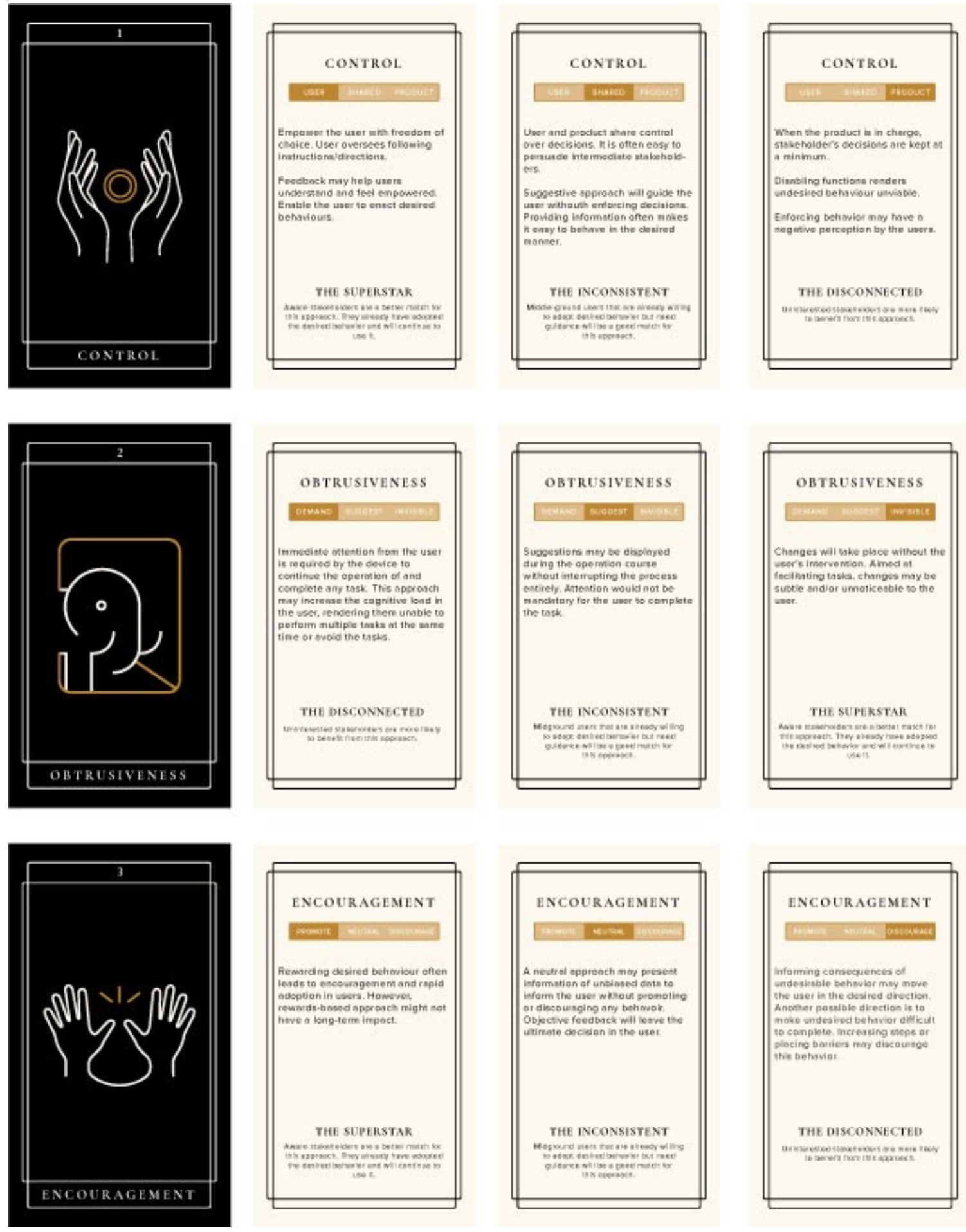

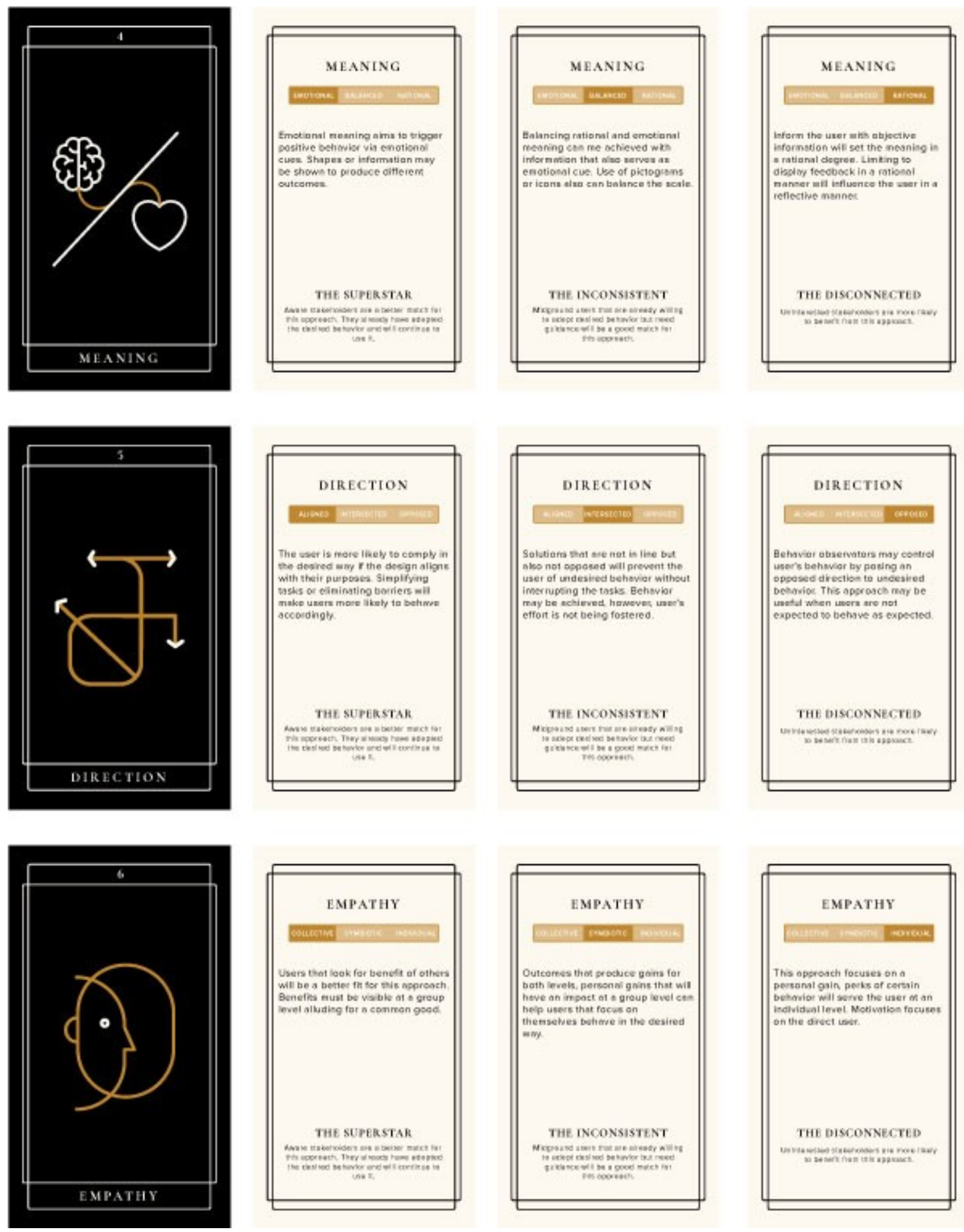

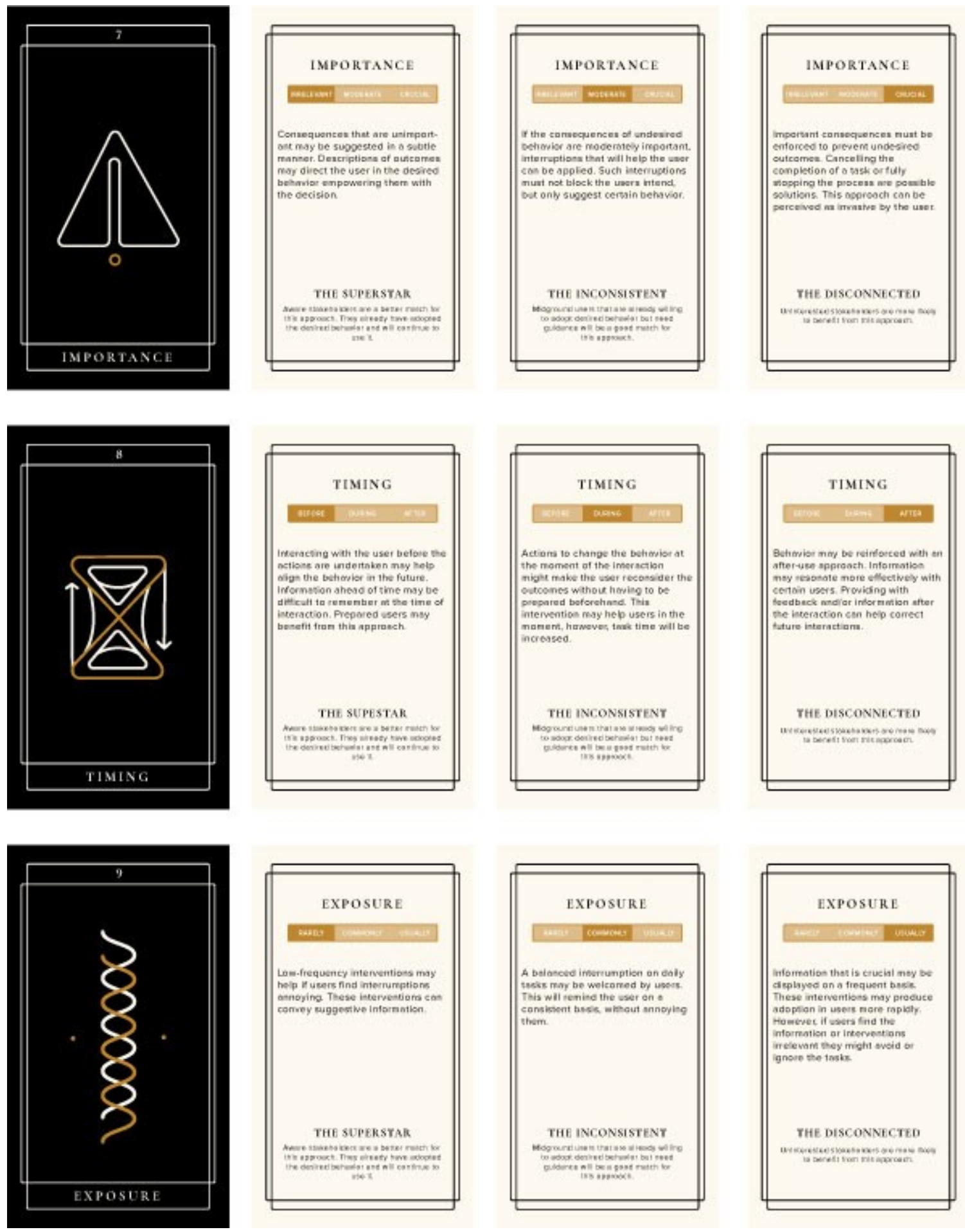